\title{
Explaining Declines in US Rural Mortality, 1910-1933: The Role of County Health Departments
}

\author{
Lauren Hoehn Velasco ${ }^{12}$
}

\begin{abstract}
This study estimates the impact of an American rural public health program on child mortality over 1908 to 1933 . Due to the absence of sanitation and childoriented health services outside of urban areas, public and private agencies sponsored county-level health departments (CHDs) throughout the US. Variation in the location and timing of the CHDs identifies improvements in population health, which are captured entirely by children. Mortality declines emerge in infancy and gradually decay through childhood. Adversely affected areas with either an ample population of nonwhites or greater levels of preexisting infectious disease undergo larger reductions in mortality.
\end{abstract}

JEL codes: I15, I18, N31, N32, O12, O18.

Keywords: mortality, health, development, rural population, demographic transition.

\footnotetext{
${ }^{1}$ Boston College, Department of Economics, Chestnut Hill, MA 02467. Email: lauren.hoehn@bc.edu

${ }^{2}$ I am grateful to Claudia Olivetti, S Anukriti, Scott Fulford, Robert Margo, and Jacob Penglase for their for their gracious feedback on this project. I thank all the participants at the Boston College Applied Micro Workshop, the Boston College Dissertation Workshop, the 2016 NBER DAE Summer Institute, and the 2016 EHA Annual Meeting for their valuable suggestions and comments.
} 


\section{Introduction}

Preventable causes of death continue to threaten the lives of infants and children in the developing world. Reducing fatalities of children under the age of five is a principal priority stated in the 2015 Millennium Development Goals (MDG [2015]). Inadequate sanitation and health services explain a crucial piece of the health gap dividing affluent and underdeveloped countries (MDG [2015]; WHO [2016]). Such services are even more inadequate in rural areas, and as a result, rural regions suffer twice the child mortality when compared with neighboring cities (UNICEF [2015]). Creating effective contemporary policy relies on our ability to identify public health measures that restrain child mortality.

Studying the determinants of low child mortality in the developed world affords the ideal backdrop to determine effective policies. During the early twentieth century, the US experienced rapid declines in child mortality. In 1917, children between one and four made up $7.5 \%$ of all deaths, and by 1934 the percentage had declined to $4 \%{ }^{3}$ For infants, the death rate nearly halved, decreasing from 100 per 1,000 births in 1915, to 53 deaths per 1,000 births in 1933. ${ }^{4}$ The improvements in child mortality appeared in both rural and urban areas. This widespread progress is distinct from modern developing countries, who struggle with access in rural regions. These reductions are plausibly attributable to improvements in sanitation and basic care as the decline took place before the antibiotic and sulfa drug era. ${ }^{5}$

This study concentrates on a widespread rural public health intervention that took place over the years 1908 to 1933. Public health authorities instituted county health departments (CHDs) to improve sanitation and primary health services. Advancements in sanitation occurred through inspections, hygiene training, and installation of toilets, wells, and drainage. Health services directly targeted child health through exams, nutritional consults, immunizations, and midwife hygiene training. Sponsorship for CHDs came from outside organizations including the US Public Health Service, state governments, the Rockefeller Sanitary Commission, and the Sheppard-Towner Act.

In the US historical literature, the majority of studies focus on state and city-level efforts. Related studies have linked improvements in city water sanitation and sewage removal to declines in adult and infant mortality. Particular studies include Alsan and Goldin [2015], Troesken [2001], Haines [2001b], Troesken [1999], and Cutler and Miller [2005]. Prior work has also documented the benefit of more unified public health ef-

\footnotetext{
${ }^{3}$ These percentages are based on the rural state-level mortality data.

${ }^{4}$ US Vital Statistics 1933, pp 11.

${ }^{5}$ Jayachandran et al. [2010] Sulfa came on the market in 1937. Antibiotics in the 1940s.
} 
forts across several states. Studies such as Olmstead and Rhode [2004], Bleakley [2010], and Moehling and Thomasson [2012] find reduced state-level mortality with broad public health efforts. Two closely related studies, Moehling and Thomasson [2014] and Bleakley [2007] have considered similar funding initiatives in slightly different contexts. Moehling and Thomasson [2014] examines the Sheppard-Towner Act and finds decreased infant mortality in targeted states. Bleakley [2007] finds improved long-run outcomes for children exposed to the Rockefeller Sanitary Commission hookworm eradication efforts.

Studies focusing on rural public health investments during the mortality transition are fewer in the US literature. The main paper addressing rural morality, Higgs [1973] considers the period leading up to the start of this study, 1890-1915, and concludes that declines in mortality were precipitated by an improved standard of living. Higgs [1973] claims mortality reductions cannot be associated with public health appropriations, as few were made outside of cities. While the CHD movement cannot explain the majority of the mortality transition, it does provide evidence of public health investment in rural areas. Another related study during the 1960s, Bailey and Goodman-Bacon [2015], considers a roll out of Community Health Centers (CHC) in under-served communities. The authors find these CHCs are associated with a mortality decline for those over 50 . In the development literature, studies note that in rural areas, the low-density setting forces initiatives to behave differently than high-density urban neighborhoods. Clasen et al. [2007] and Wolf et al. [2014] systematically review the literature and find that the majority of benefits in the rural setting come from sewage based interventions. Geruso and Spears [2015] and Duflo et al. [2015] attribute the small effect of sanitation efforts to negative externalities that occur when facilities target only a fraction of a community. ${ }^{6}$ In the literature, there is still an open question as to how to provide cost-effective public health services in low-density areas.

This paper tracks the roll out of CHDs throughout the United States to identify the mortality effects in the targeted area. The empirical strategy exploits variation in the timing, location, and intensity of investment to estimate the reduction in overall, child, and infant mortality. Baseline results show that the initiation of a CHD improved infant and young child outcomes. Overall, investments reduced two infant deaths per 1,000 births. Separately considering black infants intensifies the reduction to eight deaths per 1,000. These results persist after accounting for the downward state-level trends in mortality. In fact, $7-10 \%$ of the period decline in mortality can be explained by health investments. $^{7}$ The magnitude of this result is similar to the reduction in state-level mortality due to the Sheppard-Towner Act found in Moehling and Thomasson [2012].

\footnotetext{
${ }^{6}$ The authors focus on toilet coverage and note benefits found with $100 \%$ household coverage.

${ }^{7}$ In rural sections of counties, infant mortality was 88 per 1,000 births in 1917 and declined to 62 by 1934.
} 
For children between one and four, CHDs prevent one death per 1,000 births. Older children and adults, conversely, only show slight declines. Any effect present in overall mortality is likely due to improvements that are realized by the age of five.

Exploiting differences by funding source bolsters the plausible exogeneity of the movement and establishes mortality reductions by health priority. Each participating organization operated with set priorities that influenced the focus of the CHD. Benefits are expected to be highest for agencies concentrating on child health as compared with more generic funding sources. Findings confirm this hypothesis and show that areas receiving a greater portion of financing from child-health interested organizations experienced more significant reductions in mortality.

Following the literature, ${ }^{8}$ concern over endogenous treatment assignment is addressed using cross-area differences in preexisting infectious disease deaths. Areas enduring a larger fraction of deaths due to communicable illness have a greater propensity to improve health outcomes than areas with elevated levels of chronic conditions. This heterogeneity in pretreatment conditions provides an improved treatment assignment. The baseline indicator is adjusted to reflect the proportion of deaths due to infectious disease in the pre-investment period. Findings here confirm the baseline and show that areas with a higher number of preexisting infectious disease deaths undergo larger reductions in mortality

This study proceeds as follows. Section II covers the history of the health investment. Section III presents the empirical strategy. Section IV describes the data employed. Section $\mathrm{V}$ displays the preliminary results. Section VI performs robustness checks. Section VII concludes.

\section{Background}

At the beginning of the twentieth century, $60 \%$ of the US population lived in rural areas with sparse public health infrastructure. By 1908, a national desire to spread sanitation prompted the initiation of CHDs. These health units served rural areas including cities with less than 10,000 people. The movement sought "communicable disease control measures, sanitation of private homes and public places, malaria prevention, tuberculosis control, goiter prevention, infant and maternity hygiene, venereal disease prevention, and school hygiene" (Lumsden [1920-30], pp 2616). CHDs operated under the direction of a full-time health officer along with assistance from nurses, inspectors, and clerks. The

\footnotetext{
${ }^{8}$ See Bleakley [2007] and Acemoglu and Johnson [2007].
} 
broad nature of the health investment attracted attention from private and public funding sources. The five primary sources of funding included: The Rockefeller Foundation (RSC), the US Public Health Service (USPHS), state health funds, the Sheppard-Towner Act, and local county authorities. ${ }^{9}$ For the initial years, CHDs were financed internally but accepted external consultation from national organizations. In 1915, outside aid from state governments, the USPHS, and the RSC appeared. ${ }^{10}$ In the $1920 \mathrm{~s}$, multiple independent and government funds assisted the movement, with each helping to direct the primary focus of the local health officials. Most notable was the Sheppard-Towner Act, which targeted infant health throughout the nation.

\subsection{History of Funding}

The nation's first CHD was internally funded and opened in Jefferson County, Kentucky. For increased adoption throughout the country, outside consultation was needed. In 1911, the USPHS piloted a rural health department in Yakima County, Washington. This CHD worked to contain typhoid fever - a water-borne and food-borne infectionthat caused a threefold mortality rate in the U.S. relative to comparable nations. ${ }^{11}$ In Yakima County, the USPHS helped to institute improvements in irrigation and water sanitation. These efforts produced a steep decline in typhoid-specific mortality. After successes in the West, the movement extended to the impoverished South. The USPHS spread water sanitation to control typhoid fever and related diseases of filth, nutritional changes to reduce pellagra, and mosquito control to prevent malaria. Through these measures, the USPHS reduced instances of all three ailments, demonstrating that full-time local health units were effective at reducing targeted illnesses.

Simultaneous to the USPHS, in 1910 the RSC created a five-year partnership with state health departments to improve conditions in 11 states from Virginia to Texas (see Bleakley [2007]). In 1915 the RSC efforts transitioned into a partnership with countylevel officials, contributing directly to the CHD budget. Health department funded by the RSC were interested in benefiting child health through a reduction in diseases of filth and improvements in basic care (Ferrell et al. [1936]).

The 1920s marked the appearance of grants designed specifically to target infant and maternal mortality. In 1921, the U.S. Department of Labor promoted mother and child health through the Sheppard-Towner Act. ${ }^{12}$ CHDs receiving this aid targeted initiatives

\footnotetext{
${ }^{9}$ The Rockefeller Foundation funded activities through the Rockefeller Sanitary Commission (RSC), Fosdick [1952] pp 38-41.

${ }^{10}$ Fosdick [1952] pp 38-41, Ferrell et al. [1936].

${ }^{11}$ Hygienic Laboratory Bulletin 35, 44, 52, and 72.

${ }^{12} \mathrm{MA}, \mathrm{CT}$, and IL opted out of this program.
} 
towards prenatal and infant exams, training of midwives, and spreading mother-infant hygiene information. Outside of this Act, individual donors supported infant-child health in Kentucky, Ohio, and Michigan. Kentucky's Mary Breckenridge contributed to to the budget of counties targeting infant and young children's health. The Children's Fund of Michigan heavily supported mother-infant health and contributions surpassed state and national funds.

By 1931, approximately 600 counties had CHDs, ${ }^{13}$ with $88 \%$ receiving a portion of outside funding. Even though the bulk of annual funding came from internal county funds, most counties required an outside incentive to begin improving the health of residents. ${ }^{14}$

\section{$2.2 \quad$ Activities}

To understand the nature of the sanitation and health services a sample of 132 CHD's activities are provided in Lumsden [1920-30], with an example entry in Table A.1. Figure I and Table 1 display the distribution of the key sanitation and the medical services. All estimates are averaged over years 1925-1928.

Initially, CHDs were focused on improving sanitation to reduce diarrheal diseases. This was accomplished through increased access to toilets, wells, and drainage. Sewage and drainage improvements moved waste away from water supplies and effectively reduced diarrheal disease. Alongside this main goal, initiatives worked to inspect public areas, food, and milk. These inspections worked primarily to reduce typhoid fever and tuberculosis. Additional efforts worked to publicize information on proper hygiene and nutritional improvements. Figure I displays the percent of sanitation services by principal activity. To aggregate the data, included activities are those that require the presence of a trained staff member. This requirement would include the installation of a toilet, or the number of lectures given, but would exclude the number of bulletins handed out or the attendance at a lecture.

Medical services were the second major effort of CHDs. Beginning in the 1920s most departments employed a nurse to administer treatments, exams, and consultations. These initiatives were specifically concerned with the health of infants and young children. Health officers and nurses worked together to provide advice, conduct exams, and to instruct midwives and schools in proper sanitation. Medical efforts in addition to exams attempted to quell the spread of infectious disease. Vaccinations were distributed for

\footnotetext{
${ }^{13}$ Historical documents report fewer health departments because districts of health departments were enacted for a few county groups. District health departments served counties in groups. To deal with this issue districts are split equally over counties.

${ }^{14}$ Duffy [1992], Ferrell et al. [1936].
} 
smallpox, typhoid, and diphtheria. ${ }^{15}$ Quarantines were administered, both for adults and for children. Students were excluded from public schools for communicable diseases such as diphtheria, scarlet fever, measles, and whooping cough. Table 1 presents the medical efforts per capita by category. Some of the 132 counties are lost due to lack of data on births and population for the period in question.

\section{Empirical Strategy}

\subsection{Baseline Estimates}

The baseline mortality effect of instituting a CHD in county $j$, state $s$ and, year $t$ is estimated as:

$$
M_{j s t}=\beta\left(C H D_{j, t-1}\right)+\mathbf{X}_{j t}^{\prime} \gamma+a_{j}+\eta_{t}+\phi_{s} t+\epsilon_{j s t}
$$

where $M_{j s t}$ is the mortality rate in county $j$ in year $t=1910, \ldots, 1934 . C H D_{j, t-1}$ is a measure of CHD activity in county $j$, year $t-1=1909, \ldots, 1933 .{ }^{16} a_{j}$ and $\eta_{t}$ captures county and year fixed effects. $\phi_{s} t$ are state-specific time trends. $\epsilon_{j t}$ is the regression error. $X_{j t}$ are time-varying county controls. Due to the asymmetric time and location of adoption, the estimation captures the difference between treated and untreated counties before and after health investments. Adding time trends measures the effect of the CHD at its deviation from the state trend.

Activities of the $C H D_{j, t-1}$ are captured on both the intensive and extensive margins. First, an indicator gives the primary effect of CHDs on mortality. This binary implementation equals 1 for counties with a CHD in year $t-1$ and 0 otherwise. Second, to capture the intensity of treatment, the per capita budget replaces the indicator for investment. Spending an additional dollar per person will likely confer elevated health improvements. Third, the budget is split into the fraction received by source. Funding organizations had specific initiatives and populations in mind. Residents specifically targeted by agencies funding the local CHDs should show surpassing mortality improvements. For example, areas funded by the Sheppard-Towner Fund and the Rockefeller Foundation are expected to experience greater reductions in deaths for infants and children.

\footnotetext{
${ }^{15}$ Diphtheria was technically an antitoxin, but in records is included as a vaccine.

${ }^{16} C H D_{j, t-1}$ is used in place of time $t, C H D_{j t}$ for two reasons. First, CHDs are enacted throughout the calendar year, with frequent appearances between October and December. The asymmetry of treatment throughout the year lowers the ability of the CHDs to show an effect in year $t$ since the majority of the year passed before the CHD opened. Second, it is unlikely that large volumes of spending in time $t$ will alter health outcomes in the current period and are more likely to have an effect the following year.
} 


\subsection{Pre-treatment Infection Rates}

Differing disease incidence throughout the US can be utilized to control for the propensity to both adopt and respond to treatment. Treated areas with high preexisting preventable deaths stand to improve mortality rates by more than areas suffering from high levels of chronic conditions. Following a similar methodology to Bleakley [2007], the heterogeneity of the pre-treatment infectious disease mortality enables an enhanced treatment-control strategy. The percentage of infectious disease deaths is multiplied by an indicator for the health investment:

$$
\left(\frac{\text { Infectious Disease Deaths }}{\text { Total Deaths }}\right)_{s}^{p r e} \times C H D_{j, t-1}
$$

more concisely, $I_{s}^{p r e} \times C H D_{j, t-1}$, where $I_{s}^{p r e}$ denotes the state fraction of deaths due to communicable disease over the pre-investment years. While the state-level is not ideal, due to county-level data limitations implementing the state-level measure allows for the inclusion of the full sample. County-level estimates are explored in Section 6.1.1.

Accordingly, Equation 3.1 is modified to include the treatment variable in Equation 3.2. The effect of the health investment in county $j$, state $s$, and year $t$ appears as:

$$
M_{j s t}=\beta\left(I_{s}^{p r e} \times C H D_{j, t-1}\right)+\mathbf{X}_{j t}^{\prime} \gamma+a_{j}+\eta_{t}+\phi_{s} t+\epsilon_{j s t}
$$

where the full effect of the intervention is now the disease-specific mortality augmented by the indicator for the CHD, $I_{s}^{\text {pre }} \times C H D_{j, t-1}$. For implementation, pre is defined as the average over the two years before instituting a CHD.

The above specification differs slightly from Bleakley [2007] as the location of the intervention is observable. In Bleakley [2007] all areas were given a weight based on the initial levels of hookworm under a difference-in-differences framework. Here the adjusted indicator is introduced during the CHD year and county in a panel of treated years. Never treated counties continue to receive a zero, as in the base binary assignment. This calibrated measure captures the effectiveness of the CHD reducing infectious disease deaths.

Identification in either context depends on the assumption that populations suffering from high levels of acute preexisting illnesses will respond to sanitation measures with greater reductions in mortality than areas with lower levels. This hypothesis is plausible 
given that areas with elevated levels of chronic or age-related deaths should not benefit from the CHD. To test this assumption, Figure II shows the log ratio of the deaths in 1934 to 1910 plotted against the fraction of deaths due to infectious disease. As expected, higher levels of infectious disease are associated with larger declines in mortality. Further checks on this assumption follow in Section 5.5.

Estimation is implemented under two definitions for $I_{s}^{\text {pre }}$, acute infectious disease and all infectious disease, with tuberculosis (TB) excluded from acute. TB is singled out for two reasons. First, the nature of the disease progression enables individuals who contract it to live as many as 15-20 years before succumbing. Due to the lengthy time span between infection and death, CHDs are expected to have a smaller effect on TB. Second, TB made up a significant portion of deaths in the early twentieth century, and due to this, will impact results. Adding TB to the second definition of infectious disease provides a useful test for the endogeneity correction. If the mortality response is higher under the acute definition, the correction falls in line with expectation.

\section{Data}

\subsection{Health Investment Data}

Health investment data originates from the History of County Health Organizations published in Ferrell et al. [1936] and tracks the implementation of CHDs over years 1908 to 1933. Data includes the yearly staff employed as well as the annual budget by source. The original document for two example counties appears in Figure A.2. The full dataset is new to the literature, with the exception of the CHD roll out in North Carolina, which has been studied in Fox [2015].

Figure III shows the distribution of health units by funding type across the US. The map shows a cluster of departments in the South, sporadically in the West, and throughout Michigan and Ohio in the Midwest. The middle of the nation, as well as the Northeast, have limited investment from this movement. In the top two maps, child health funding from the RSC and mother-infant lightly overlap, but the RSC surfaces chiefly in the South and Southwest. The mother-infant funds appear peppered throughout Michigan and Ohio, as well as the Southeast and Northwest. The bottom two maps display the distribution of USPHS and state funds. Almost all health departments received some amount of money from the state government, and a substantial number received funding from the USPHS. 
CHDs ideally provided a budget of $\$ 10,000$ for a county with 25,000 individuals, alongside a staff of one medical director, one nurse, and one inspector. Table 2 Panel A provides summary statistics of the budget and staff over years 1910 to 1933. The first set of columns provides the total amounts. The second shows the percent of the total for both the staff and the budget. From the top three rows, the mean CHD met expectation, having roughly two nurses and one inspector with a budget of $\$ 13,908$.

Identifying the source of funding received by each county is informative for distilling the aim of the CHD. Organizations that targeted child health, the RSC and motherinfant funds, are of primary interest. Table 2 breaks out the budget by source, and while these two groups make up a small portion of the total budget, their presence in a particular CHD indicates a focus on improving child health. On average, mother-infant funds provide $3 \%$ of the budget ${ }^{1718}$ and the RSC contributed $4 \%$ of the average budget. CHDs funded by child health organizations help identify the areas that should experience the strongest health effects for children.

Figure IV presents a time-varying display of the budget and staff. In the top graph, the start of the movement is funded mainly from internal county funds with no existing outside funding. In 1915, all categories of external financing grew increasingly until the 1920s. The child health funds follow the same pattern. Child funding sources remain relatively constant throughout the 1920s.

Considering the number of staff in the bottom of Figure IV, the mean number of nurses follows a similar pattern to the external funding sources. Nurses begin to appear around 1915, with the average number of nurses growing into the 1920s. The number of medical officers and inspectors remains consistent throughout the movement. This pattern indicates that health departments in early years focused on sanitation efforts. Likely, the increased employment of nurses came from outside desire to provide medical services. By the beginning of the 1920s, nurses are supplied at a higher level than the other two staffing types.

\subsection{Mortality Data}

To measure health effects, an unbalanced panel of county-level rural mortality data has been digitized from the United States Vital Statistics [1890-1938]. The original data table appears in Figure A.3 and A.4. This data provides the number of overall deaths,

\footnotetext{
${ }^{17}$ The mother-infant category includes the Sheppard-Towner Fund, the Children's Fund in Michigan, and individual donors in Ohio and Kentucky.

${ }^{18}$ Some Michigan counties received $100 \%$ of the budget coming from the Children's Fund of Michigan.
} 
infant deaths, stillbirths, births, and population for each county, excluding towns larger than 10,000 . One limitation of the mortality data is that states reported deaths asymmetrically. Many of the southern states began reporting late in the 1920s. Section 6.3 provides a subset of the main analysis with a balanced panel. Appendix Table 14 presents the full sample years available for each state. The advantage of this limitation is that states were not admitted to the official statistics until they provided accurate mortality figures, which limits the concern of measurement error.

Figure V provides a time-varying display of the mortality data. The top two panels show the overall and infant mortality for available years. Throughout the period, there is a decline in rural mortality, which follows the national trend. In 1910, the crude death rate in the rural United States was 132.7 per 10,000. By 1934, it had declined to 98.8. Infant mortality dropped by a similar amount starting at 88 per 1,000 births in 1917 and falling to 62 in 1934. Figure VI presents a dynamic display of overall and infant mortality throughout the nation. This map highlights within-state variation for both children under one and the overall death rate.

The bottom left graph displays the stillbirths. Since health department efforts included training midwives and conducting prenatal exams, stillbirths are a useful measure of gestation quality. Over the available years, 1922-1924, there initially appears to be a decline and then a sudden spike over 1927-1928. This spike is likely driven by definitional changes or alternations in measurement, as there is not a clear definition in place throughout the United States. The 1927-1928 spike is followed by another decline in stillbirths.

The final graph in the bottom right displays the calculated child mortality rate for age groups: one to four and five to fifteen. This figure shows a similar decline over the period in question. Calculation of county-level child mortality uses the fraction of deaths by age group at the state level for rural areas multiplied by the overall mortality at the county level. ${ }^{19}$ This appears for county $j$ and state $s$ as:

$$
\text { Deaths }_{j, \text { age }_{i}}=\frac{\text { Deaths }_{s, \text { age }_{i}}}{\text { Deaths }_{s, \text { total }}} \times \text { Deaths }_{j, \text { total }}
$$

This estimation is necessary as the by age distribution of deaths is not available at the county-level.

An alternative way of calculating the age-specific death rates involves the age distribution at the county level. Unfortunately, the US population age distributions are

\footnotetext{
${ }^{19}$ Under one is excluded as it is available at the county-level.
} 
imprecise before 1930. The distribution only provides the county total and does not split into rural and urban. The lack of age-related distributions proves problematic as states were uniquely composed of urban and rural areas. The benefit of using the fraction of state-level deaths is that these are reported separately for rural areas. The case for the above approach is strengthened when considering that CHDs located in areas with higher numbers of children. If anything, the state-level deaths would put a downward bias on coefficients. As infant mortality is available at the state and county level, Section 6.4 compares the two estimates against each other in to alleviate remaining concern.

Table 2 Panel B provides summary statistics for the mortality data. The top five rows, deaths, population, stillbirths, infant deaths, deaths, and births, are directly from the mortality statistics. ${ }^{20}$ The age-specific deaths, and the adult deaths are based on the calculation above. Adult deaths are defined as 15 and over.

The last piece of the mortality data included is the by-cause mortality. State-level data are available from Cutler and Miller [2005] and county-level data are collected from the United States Vital Statistics [1890-1938]. The by-cause data is utilized to control for the ability of health departments to reduce mortality. Counties with higher pre-treatment death from infectious disease are more likely to respond to treatment. For this paper, infectious diseases include typhoid, smallpox, malaria, measles, scarlet fever, whooping cough, diphtheria, influenza, pneumonia, meningitis, and diarrhea for children under two. TB is added as a check, with the expectation that once TB is added, the estimated effect should decline slightly. This is due to the long course of the illness and the lack of immediate feedback in terms of mortality. Table 2 Panel $\mathrm{C}$ shows the summary statistics for state and county level percentage of death from the communicable disease.

\section{$4.3 \quad$ U.S. Census Data}

Controls for county characteristics are added from census microdata over years 19101940 as well as the US Farm Land Value data. These data sources are made available through the ICPSR via Haines [2004] and the Integrated Public Use Micro Sample (IPUMS) harmonized by King et al. [2010]. Linear averages fill gaps between the census years.

Table 2 presents the summary statistics for the controls used throughout the analysis, by the adoption of a health department. Controls include log of population, land density, the percent urban, the percent foreign-born, the percent black, the percent of household

\footnotetext{
${ }^{20}$ Population estimation is necessary for some counties reporting modest populations, and are based on census data for years 1910, 1920, 1930, and 1940.
} 
heads that are female, the percent of multigenerational households, percent of households on a farm, the average age of household heads, the percent of married households, the percent of individuals who cannot read or write, the log of the crop value, and the log of the farm value.

\subsection{Sample Selection and Summary of Data}

County boundaries need to be harmonized to combine the four data sources. Harmonization moves boundaries back to the first year in the sample, 1910. This process is completed using the procedure in Desmet and Rappaport [2015] and Rappaport [2007]. ${ }^{21}$ This adjustment slightly changes the structure of the data, but it ensures correct identification of treated areas. A second alignment splits health department efforts into the respective counties. For a few health departments, efforts served multiple counties. These efforts are divided into the individual counties and with funding and staff split by population weights.

Matching mortality data with the health investment data yields 38 states in the final sample. The years utilized are from 1910-1934 for overall deaths and 1917-1934 for infant mortality. The final data set for overall mortality mapped to county health investments and Census data includes 43,056 observations. There are 5,020 county-year combinations of observable health investment. For the infant mortality sample, 30,438 observations are present with 4,638 displaying a health department.

\section{Results}

\subsection{Baseline Result}

The binary implementation of CHD from Equation 3.1 is shown in Table 3. Here the negative sign across all measures of mortality demonstrates that the presence of a health program reduced mortality. The dependent variable in each column is a variation of county-level mortality rate at time $t$ and CHD measured at $t-1$. Panel A shows the unadjusted measures and Panel B displays the computed mortality measures from Equation 4.1.

Panel A Columns (1)-(3) tests the effect of the CHD on crude mortality. The strongest coefficient appears without controls and declines until the full specification

\footnotetext{
${ }^{21}$ I thank the authors kindly for sharing their unification files.
} 
in Column (3). After inclusion of state time trends, the effect disappears. A similar pattern appears in columns (7)-(9) for stillbirths.

Infant mortality in Columns (4) -(6) reveals a stronger link than crude mortality. The decline in deaths for infants persists into the full specification, where health investments prevent two infant deaths per 1,000 births. This more robust drop generates question over the distribution of mortality declines in the population.

To answer this, Panel B displays the relationship between opening a CHD and the calculated age-specific mortality. Here the effect is strongest for ages one to four years old (Columns (1)-(3)), reducing one death per 1,000 births. The estimated coefficient becomes smaller over ages five to 14 years old, preventing a half of a death, with weak statistical significance (Columns (4)-(6)). For adults the effect completely vanishes (Columns $(7)-(9)) \cdot{ }^{22}$

The declining effect from infancy through childhood into adulthood confirms the hypothesis that child outcomes are generating the improvements in overall mortality. Driving this decay is the fact that children who lived into adulthood had already survived the highest mortality diseases, and while they may have disease-related morbidity concerns, are less likely to die.

\section{$5.2 \quad$ Racial Differences}

For a subset of counties, mortality is separated by race for both infant and overall deaths. The sample size is limited and is roughly a quarter of the full sample. The loss results from exclusion of counties whose population is composed of more than $90 \%$ white and therefore, is selected towards areas with a large fraction of black residents.

Considering racial groups separately unfolds whether CHDs disproportionately benefited the worst off or the best off. As shown in Table 4, both infant mortality, and overall mortality are higher for the nonwhites than the white population. Nonwhite infant mortality is near twice that of whites. It is plausible that the mortality effects might move in either direction. If segregated sanitation efforts located in white neighborhoods, the CHDs would be unlikely to benefit blacks. Conversely, due to elevated black mortality, the population may be poised to take advantage of the public appropriation of available health services. Determining which of these plausible priors is dominant, aids in understanding whether CHDs served wealthier individuals or instead benefited under-served

\footnotetext{
${ }^{22}$ Calculation of 'Adult' mortality is attained by subtracting child and infant deaths from overall deaths.
} 
communities.

Table 5 presents the coefficients for Equation 3.1 estimated individually on white mortality and black mortality. Panel A shows the effect on crude mortality and Panel B on infant mortality. In Panel A, the impact on crude white and black mortality shows no statistical significance. These results are weaker than in the previous section, where crude mortality showed a slight decline without time trends. Here the coefficients show no response following the implementation of a CHD.

Columns (2) and (4) display the effect on the infant population. The estimated coefficients are stark when compared to the full sample results. For black children under one, the mortality reduction is eight deaths per 1,000 births. When compared to the baseline prevention of two deaths, the effect for black infants is almost four times the original magnitude. White infants show a muted effect with statistical significance disappearing with state time trends.

Estimates by race show that under-served populations may be driving the reduction in mortality. Surprise at the magnitude of the effect is partially quelled by the high mortality for blacks in Table 4. Infants in worse off communities are poised to benefit from the programs offered by health departments, as compared with better-off communities. This finding fits with similar studies such as Collins and Thomasson [2004], which notes that institutions interventions, such as the Sheppard-Towner Act, contributed to the decline in the racial infant mortality gap.

Remaining concern over segregation of services is possible. A plausible answer is suggested in Moehling and Thomasson [2012], where the authors note that in the SheppardTowner roll out allocated significant effort toward training midwives. As midwives often served black communities more heavily than white communities, black infants stood to gain from the health services more than whites (Ladd-Taylor [1988]). The CHD movement had a similar high emphasis on training and improving midwife services, which would imply a possible disproportionate effect on the black population of infants relative to whites. Especially if the black community took advantage of midwives more frequently than the white community (Moehling and Thomasson [2012]; Ladd-Taylor [1988]).

\subsection{Funding Variation}

Moving back to the full sample, in Equation 3.1, the indicator for CHD is replaced with funding amount and source to yield insight into advantageous sources of aid. Table 6 gives the results from Equation 3.1 with a different estimation in each row. Row (1) 
presents the funding per capita and Rows (2)-(7) display the fraction of the budget contributed from each of the primary sources: county, state, USPHS, Rockefeller, motherinfant, and other funds. Each row represents a separate estimation.

Row (1) displays the per capita effect on mortality, with the strongest mortality declines again appearing for children. Infant mortality and children between one and four both show a statistically significant drop with an increase in per capita spending. Stillbirths, adult mortality, and overall mortality are unaffected. Row (2), the fraction contributed by the county government itself, displays an effect is similar to the baseline. All measures are statistically significant, except stillbirths and adults. The more the county contributes, the healthier the children population becomes.

Rows (3) and (5)-(6) present the estimates for states, USPHS, and other unclassified sources. These measures of mortality fail to show a statistically significant effect. Either aid went to the communities lacking the propensity to decrease mortality, or their methods were ineffective.

The central sources of interest, the child health initiatives are shown in Rows (4)-(5). Both the RSC and mother-infant efforts show no or negative health effects for adults in Columns (1)-(2). These programs may have hurt adult health from either crowding out or trade-offs in the delivery of infants. For children, the effect matches with expectation. Initiatives tailored towards child health appear to benefit infants and children between five and 14 years old. For infants in Column (5), increasing the portion of either the RSC and mother-infant funds improves mortality outcomes. Stillbirths, in Column (6), show a decline for the first time in the analysis. With increased mother-infant funding the number of stillbirths per 1,000 births displays a very slight but significant reduction. The results here strengthen the hypothesis that child health improvements are explaining declines in crude mortality.

\subsection{Adjusted Treatment-Control Strategy}

To address the endogeneity concern inherent in the adoption of the CHD, Equation 3.3 modifies the treatment indicator to the preexisting fraction of deaths from infectious disease. Table 7 presents the results with a separate estimation in each row. Row (1) shows the results using acute infectious diseases and Row (2) presents all infectious. For ease of interpretation, the average proportion of deaths due to communicable disease are reported below the estimates. The coefficients indicate that adversely affected areas profited more from CHDs than other areas. The results are statistically significant for infant, and child mortality. Adult mortality, crude mortality, and stillbirths show no 
effect.

At the mean level of acute infectious disease of 0.22 , and all infectious disease, 0.31 , the adjusted treatment indicator reflects a slightly higher effect than the baseline. For children ages five to 14 years old, the baseline effect was 0.6. Here at the mean, deaths are reduced by 0.8 and 0.7 respectively, and the result is significant. For children between one and five years old, the baseline decline of 1.2 deaths is replaced with an estimated effect of 1.6 for acute and 1.5 for all. Infants still exhibit the highest reduction. 2.3 deaths in the initial estimation and here, 2.5 infant deaths under the acute definition and 2.4 deaths for all.

As expected, across all measures of mortality the acute estimated effect is lower than with the inclusion of TB. As discussed in the identification section, this result is expected, as TB has a longer time span from contraction of the disease until death. The fact that including TB decreases sensitivity to the CHD helps to confirm the use of the adjusted mortality as the treatment-control strategy.

The benefit of using the scaled measure is it allows coefficients to be interpreted according to the level of infectious disease present in an area. For counties implementing a CHD and at the 95-percentile of infectious disease, or $33 \%$ of deaths from acute communicable disease, the effect is stronger than the mean. For infants, the estimated effect would be a reduction of 3.7 deaths per 1,000 births. For children between one and four years old, the effect would be a reduction by 2.4 and for those between five and 14, a reduction of 1.2 deaths. While this impact may appear relatively large, it would not be enough to move the worst-off counties to become the best off. The standard deviation for infant mortality is around 26. Even at the highest level of preexisting infectious disease, the improvement would fail to move counties from the second standard deviation of mortality to the first.

\subsection{Factors Affecting Investment in CDCs}

Identification in the previous two subsections provides more reliable estimates if the prevalence of infectious disease is the principal factor in the adoption of a CHD. Ideally, investment decisions should not be driven by overall or infant mortality. To test this hypothesis, the likelihood of opening a CHD is estimated as:

$$
P\left(H D_{j s}=1\right)=\beta I_{s}+\mathbf{X}_{j}^{\prime} \gamma+a_{r}+\epsilon_{j s}
$$


where the probability of a CHD opening in county $j$ is tested with the state-level pretreatment deaths from infectious disease $I_{s}$ and regional fixed effects $a_{r}$. Following the state measure, the county-level infectious disease deaths $I_{j}$, are considered with state fixed effects $a_{s}$. Finally, $I_{j}$ is replaced with the average mortality over the period without a CHD. Estimation should decipher whether the leading factor affecting investment was the infectious disease level or the death rate.

Table 8 shows the results. Panel A presents the state level and Panel B shows the county level. Panel $\mathrm{C}$ displays the same analysis with the mortality rates as the dependent variable of interest.

In the first two panels, increasing infectious disease deaths positively impact the probability of enacting a CHD. Including TB limits the effect to the state-level. In Panel $\mathrm{C}$, neither infant nor overall mortality influence the investment decision. The coefficients fail to indicate that high mortality areas are more likely to invest and instead confirm that areas prone to infectious disease are selecting into treatment. Due to selection based on the preexisting infectious disease levels, the treatment strategy used in the prior section is properly addressing the increased likelihood of adoption. It appears that gains are resulting from lowering infectious disease, particularly acute illnesses.

\section{Robustness}

\subsection{Preexisiting Infectious Disease Checks}

\subsubsection{County-level Preexisting Infectious Disease}

For a select number of states, county-level by cause data is available before 1915 . While the county-level deaths provide valuable within-state variation, the cutoff year occurs before many states began reporting mortality statistics. Figure VII shows each of these data limitations. The county-level data is advantaged in the diversity of infectious disease mortality, while the state-level provides added observations. Equation 3.3 is estimated with county-level data to test the efficacy of the state-level measure.

Replacing $I_{s}$ with $I_{j}$ in Equation 3.3 gives the estimates in Table 9. Two shifts are important to note. First, for county-level estimates the pre period is the mean of years 1912 and 1914. This change accommodates the available data. Second, child mortality measures are excluded because of the smaller sample size and the limited number of states. 
Results in Table 9 mimic the state effects except for crude mortality, which shows slight statistical significance under the acute definition. For crude mortality, the average effect is a reduction by 2.4 deaths with acute infectious disease. For infants, there is an estimated reduction of 1.6 per 1,000 births for acute, and 1.3 when including TB. As expected, the estimated effect shrinks when introducing TB across both overall and infant deaths. While the coefficients are slightly smaller in the county-level than compared with the state-level, they are in a similar range of effect. This estimation helps to confirm the state-level estimates from the primary results.

\subsubsection{Preexisiting Definitional Shift}

A second check robustness check for $I_{s}$ appears in Table 10. Here the estimation reverts to the state-level definition, with the pre-period extended from two years preimplementation to five years prior. This check serves to acknowledge that the results are not driven by a shock in the short pre-period, but reflect the actual conditions in the treated areas. The coefficients appear similar to the baseline. For children between five and 14 years old one-half of a death is prevented. For children between one and four, the effect is by roughly one death. Infants show the largest decline of two deaths.

\subsection{Heterogeneity of Effect}

Estimates up to this point have reflected the lag implementation of CHD. This specification rests on the supposition that investments did not improve health instantaneously at time $t$. Intuitively, access to a CHD should produce changes in the population over one or two periods as health services and sanitation are rolled out. To quell fear over a spurious relationship estimates are expected to display a lack of effect prior to implementation, and again a few periods after investment.

To verify the mortality effect coincides with the adoption of a CHD, the heterogeneity of effect is estimated as:

$$
M_{j t}=A(L) C H D_{j t}+\mathbf{X}_{j t}^{\prime} \gamma+a_{j}+\eta_{t}+\epsilon_{j t}
$$

where $M_{j t}$ is the county mortality rate in time $t . A(L)$ is the polynomial lag (and lead) operator. $C H D_{j t}$ is a binary variable for existence of a health department in county $j$ in time $t . a_{j}$ are county fixed effects. $\eta_{t}$ are time fixed effects. 
Coefficients are expected to be negative across all lags of $A(L)$. Based on preceding reasoning, the first and second lags should show the strongest intensity and significance. Over each lag and lead there should be no effect at time $t$ or prior to time $t$, as improvements in sanitation are expected to have a slightly delayed effect.

Table 11 presents the results from Equation 6.1. Panel A shows multiple lags and Panel B shows leads. Considering the lag of the CHD in Panel A, Columns (1) and (4) show three, Columns (2) and (5) display five, and Columns (3) and (6) extend the lag structure out to seven. Variations of this structure show similar results.

Columns (1)-(3) present the effect on the crude mortality. The largest coefficient repeatedly occurs at $t-2$, with a positive shock at time $t$. Health improvements take place in the year following implementation, with the relationship persisting after adding additional lags. Columns (4)-(6) display the same estimation with infant mortality. Here the results show the largest effect two periods after investment. The coefficients in columns (1)-(4) reflecting a magnitude similar to the baseline, a mortality reduction by two infant deaths per 1,000 births.

To test whether mortality declined before adopting a CHD, Panel B shows the leading effect. The coefficients fail to show a clear relationship between the CHD and mortality. The lack of response before opening a health department eases concern over a spurious relationship between mortality and the CHD. Further, the estimates above confirm the use of the lagged CHD indicator the main specification of interest and yield credibility to the claim that CHDs are the mechanism for improving mortality.

\subsection{Restricted $\mathrm{t}$}

In the baseline estimation, first adopters have the advantage of a longer horizon to improve health. Instead of considering the average effect over the whole post period, estimates are restricted to a limited term after the health investment. Limiting the time horizon helps mitigate remaining concern over trends in mortality driving the result. This restriction, combined with the asymmetric timing of treatment alleviates overstating the baseline effect. Equation 3.1 is re-estimated with the condition:

$$
C H D_{j, t-k}=0
$$

where $k$ is the number of years after implementation the estimates are restricted over.

Table 12 Panel A shows the restricted results two years post-implementation. Columns 
(1) and (2) show no effect on crude mortality or adult mortality. Children of all ages respond with a statistically significant decline in mortality. Children between five and 14, show a reduction by 0.6 , those between one and four show a decrease by 0.8 , and infant mortality is reduced by 1.7 deaths per 1,000 births. These coefficients are slightly smaller than the baseline effect but remains in a similar range of effect. The restricted period provides a more precise statement of the impact of the CHD than the baseline result.

In Panel B, to test the sample on a balanced panel, the sample is limited to the years 1920-1934. States that fail to report mortality statistics by 1920 are excluded. Here the results are similar to the above, where infants show a reduction of slightly less than two deaths per 1,000 births and children between one and four years old show a reduction by roughly one death. These estimates confirm the inverse relationship between age and health benefits. The younger the child, the larger the estimated coefficient, with the reduction disappearing in adulthood.

\subsection{Additional Tests}

Estimates are tested over base assumption with sample adjustments to ensure results are robust. Table 13 presents four adjustments of Equations 3.1. Panel A shows the results restricted to the infant sample and replaces county infant deaths with state-level infant deaths. Panel B displays the estimation using logarithmic mortality. Panel C shows the results with county-level time trends, and Panel D drops population outliers.

Throughout this paper, the infant data is more limited in scope that the overall mortality. Infant mortality was not collected until 1917, while overall mortality began in 1910. Here overall mortality is adjusted to remove infant deaths and estimated over the same sample as infants. Panel A shows the results from this correction in Column (1). Here crude mortality maintains its lack of significance effect, implying that the infant mortality sample is not more inclined to show reductions in mortality. This result further strengthens the supposition that all reductions in mortality are driven by children.

In Columns (3)-(5) the results are repeated, with the one distinction, state-level calculations of infant mortality replace the county level measure. This serves to check the accuracy of the state-level measure against the known county-level estimates. Here using the state-level infant mortality, the coefficient of 2.36 is almost the equivalent to the baseline 2.26. This similarity bolsters confidence in the state-level child mortality results used throughout this paper. As the infant mortality outcomes are remarkably similar across the state and county measures, the thought would be the child mortality measures would be likewise comparable. 
Panel $\mathrm{B}$ checks that mortality reductions are not driven by the functional form assumption. $M_{j}$ st is replaced by $\ln m_{j s t}$ in Equation 3.1. Columns (3)-(5) show a similar, if not stronger, result to the baseline. This confirms coefficients are not driven by the functional form decision.

Panel $\mathrm{C}$ replaces the state time trend with county time trends. Here the childhood mortality effects are similar, but the infant mortality estimate drops slightly. As these results take out all of the county-time effects, they should be considered a lower-bound for the improvements in child mortality.

Panel D displays the original estimation, excluding counties in the tails of the population distribution. Limiting the sample to exclude the $5 \%$ upper and lower tails ensures that outliers are not driving the results. Here results appear similar to Panel C.

The robustness checks confirm the original intuition and indicate that infant and child mortality are relatively robust to specification and sample shifts. For infants, the effect is roughly two deaths prevented in the post period. For children between one and five years old, the effect is about one death per 1,000 births. For older children up to 14 years old, the effect is small, about half of a death is prevented. Overall mortality results are suspect and are likely driven by childhood health improvements. This statement confirmed when child deaths are removed, and the remainder of adult deaths shows no effect.

\section{Conclusion}

This study finds evidence that CHDs in rural US counties improved child health. The findings contribute to our understanding of public health services that influenced the US mortality decline of the twentieth century. Results find a clear benefit to basic health and sanitation services overseen by a trained staff member.

The results confer a consistent mortality decline for children, with a decaying trend into adulthood. Mortality reductions are strongest amongst children under five. Estimates reflect a reduction by between one and three infant deaths per 1,000 births over 1917 to 1934, with the majority of the benefit occurring two years after adopting a CHD. For children between one and four, the effect is between one and 1.5 deaths per 1,000

births. Slightly weaker reductions are found for children between five and 14 years old, with the effect disappearing for adults.

Areas reporting mortality by race exhibit a disproportionately large effect on non- 
white infants. Investments reduced black infant deaths by eight per 1,000 births. The magnitude of the effect is four times the baseline effect and indicates that CHDs were aiding adversely affected areas rather than wealthier areas. Similar findings occur when adjusting the investment indicator to the preexisting proportion of deaths from infectious disease. Regions with higher levels of infectious disease show greater reductions in mortality. Results here confirm the hypothesis that CHDs improved outcomes through the reduction in infectious disease deaths.

The evidence for reductions in child mortality has application in today's developing countries, where a struggle to implement effective policies prevails. In cases where similar services do exist, staff suffers absences that may impact the quality of services (Chaudhury et al. [2006]). The US experience provides a useful guide for the deployment of basic health services to adversely affected areas. Such programs would likely be more fruitful in the contemporary setting as novel medical technologies are readily available. 


\section{Figures and Tables}

Figure I: Sanitation Efforts of CHDs, 1925-1928

Sanitary Efforts, Percent of Total

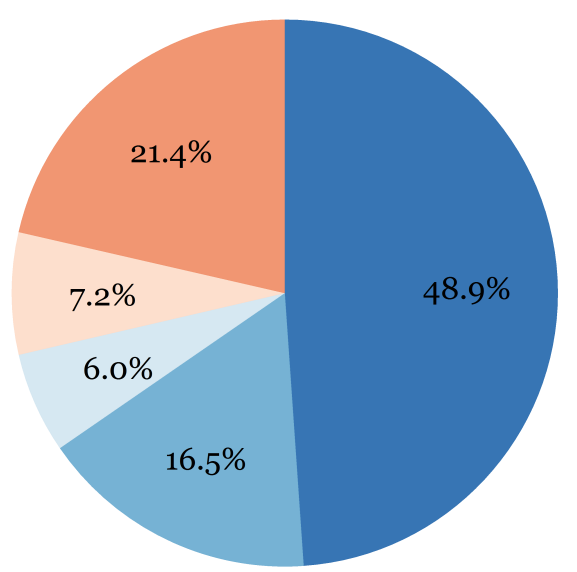

Sanitary Inspections

Nutritional Advice

Privies, Wells Sewers Installed
Food Inspections

Lectures and Exhibits

Note: Figure excludes activities that did not require presence of trained health worker. Data sourced form Lumsden [192030]. 
Table 1: Medical Efforts of CHDs, 1925-1928

\begin{tabular}{lcc}
\hline \hline & & \\
& Mean & SD \\
\hline School Children Per Child 5-14 & 0.67 & 0.68 \\
Prenatal Efforts Per Birth & 0.47 & 0.96 \\
Infant Efforts Per Child 0-4 & 0.38 & 0.63 \\
P.C. Vaccines & 0.11 & 0.13 \\
P.C. TB Efforts & 0.05 & 0.10 \\
P.C. Quarantines & 0.04 & 0.08 \\
P.C. Defects Corrected & 0.02 & 0.03 \\
P.C. Venereal Efforts & 0.02 & 0.05 \\
\hline \hline
\end{tabular}

Note: Infant, school children, and prenatal include efforts such as exams, consults, and home visits per the estimated population. All other figures are per capita for the whole county population. Data sourced from Lumsden [1920-30]. 
Figure II: Ratio of Deaths 1910 to 1934 by Ratio of Deaths

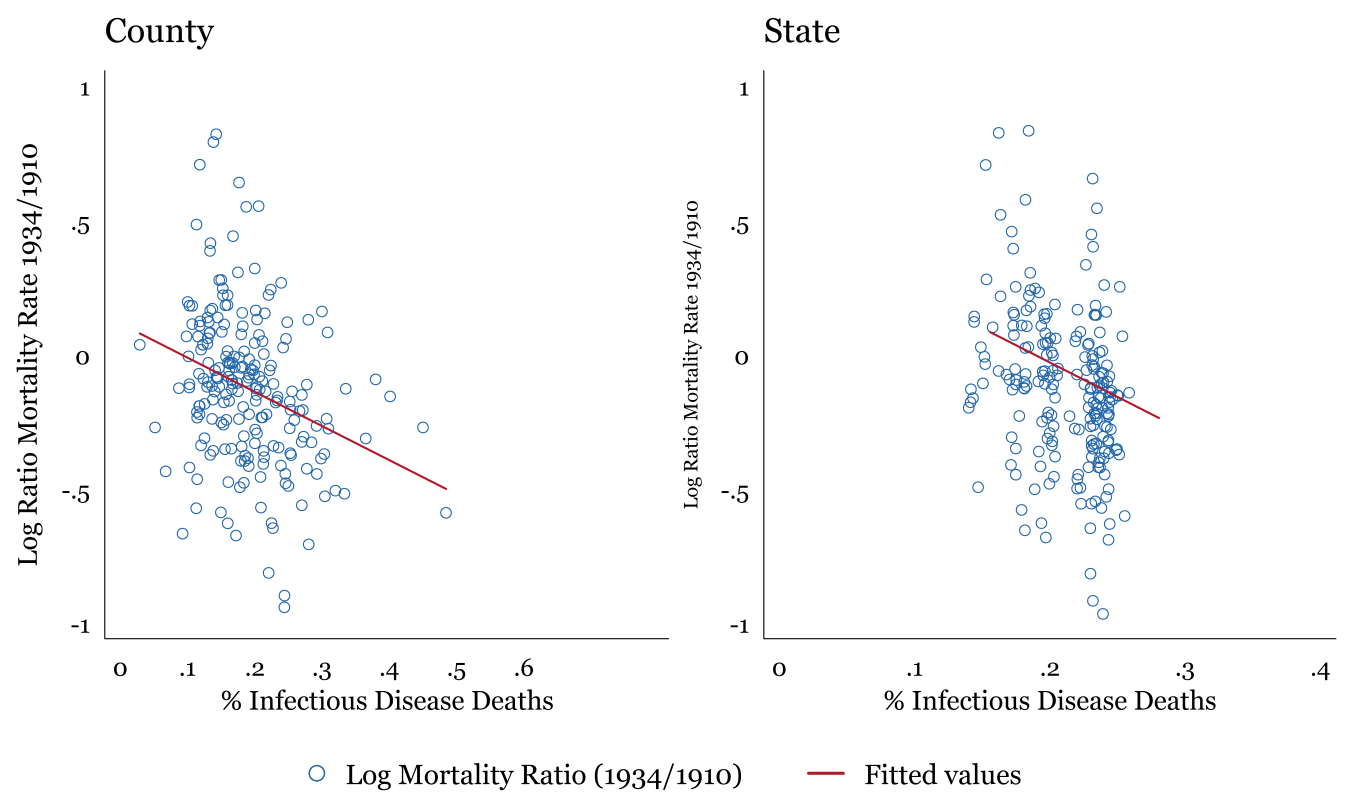

Note: Data source from US Vital Statistics. 
Figure III: Distribution of Funds
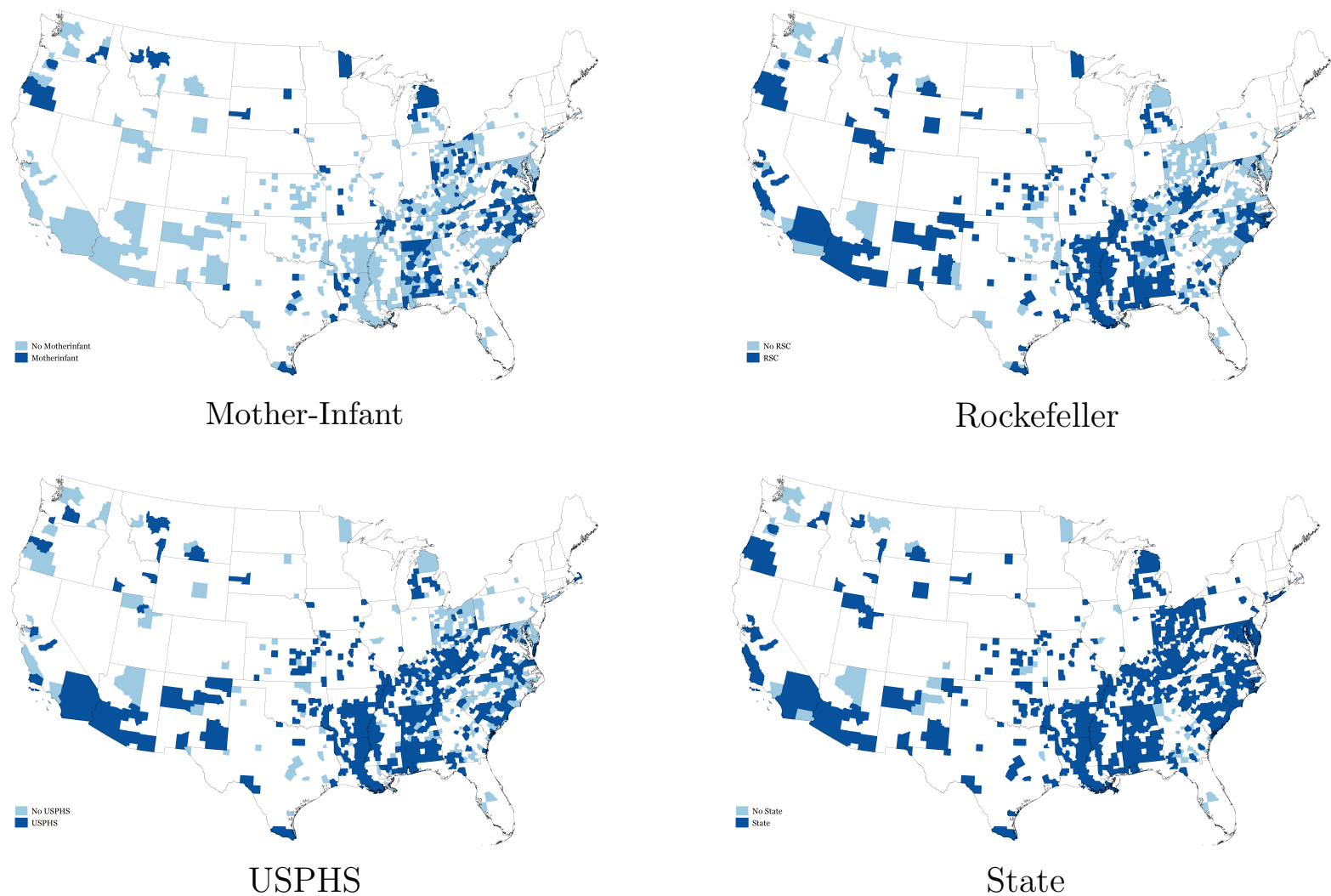

Note: Data sourced from U.S. Public Health Bulletin 222. 
Table 2: Summary Statistics

\begin{tabular}{|c|c|c|c|c|c|c|c|c|c|c|c|}
\hline & \multicolumn{7}{|c|}{ Total } & \multicolumn{4}{|c|}{ Percent of Total } \\
\hline & \multicolumn{2}{|c|}{ Mean } & \multicolumn{2}{|l|}{$\mathrm{SD}$} & Min & \multicolumn{2}{|c|}{$\operatorname{Max}$} & Mean & $\mathrm{SD}$ & Min & Max \\
\hline \multicolumn{12}{|l|}{ Staff } \\
\hline Total & \multicolumn{2}{|c|}{6} & \multicolumn{2}{|l|}{19} & 1 & \multicolumn{2}{|c|}{541} & 100 & 0 & 100 & 100 \\
\hline Nurses & \multicolumn{2}{|c|}{2} & \multicolumn{2}{|l|}{6} & 0 & \multicolumn{2}{|c|}{191} & 32 & 17 & 0 & 87 \\
\hline Inspectors & & & 4 & & 0 & 86 & & 15 & 15 & 0 & 89 \\
\hline Budget & & & & & & & & & & & \\
\hline Total & 13 , & & 45,88 & & 167 & 1,375 & 496 & 100 & 0 & 100 & 100 \\
\hline County & 10 , & & 45,41 & & 0 & 1,375 & 496 & 59 & 26 & 0 & 100 \\
\hline State & & & 3,915 & & 0 & 113 & 310 & 22 & 18 & 0 & 100 \\
\hline USPHS & & & 1,191 & & 0 & 17,9 & 09 & 7 & 13 & 0 & 89 \\
\hline $\mathrm{RSC}$ & & & 827 & & 0 & 18,0 & 82 & 4 & 8 & 0 & 50 \\
\hline Mother-Inf & & & 759 & & 0 & 9,9 & & 3 & 12 & 0 & 100 \\
\hline Other & & & 3,041 & & 0 & 96,4 & 138 & 5 & 11 & 0 & 86 \\
\hline Observations & & & & & & & & 5020 & & & \\
\hline & Pane & B: $\mathrm{S}$ & umme & $\operatorname{arys}$ & Statis & tics for & Mortal & lity Stat & atistics & & \\
\hline & & & No 1 & $\mathrm{HD}$ & & & & & $\mathrm{HD}$ & & \\
\hline & Mear & $\mathrm{SD}$ & Min & & Max & $\mathrm{N}$ & Mean & SD & Min & $\operatorname{Max}$ & $\mathrm{N}$ \\
\hline All Deaths & 239 & 257 & 1 & & 4,670 & 30,269 & 346 & 408 & 4 & 9,051 & 12,769 \\
\hline Population (K) & 21 & 20 & 0 & & 290 & 30,286 & 31 & 33 & 2 & 596 & 12,770 \\
\hline Stillbirths & 15 & 16 & 1 & & 267 & 17,277 & 28 & 30 & 1 & 428 & 7,481 \\
\hline Infant Deaths & 30 & 41 & 1 & & 922 & 21,151 & 50 & 60 & 1 & 1,377 & 9,287 \\
\hline Births & 429 & 440 & 1 & & 7,060 & 21,332 & 672 & 682 & 6 & 11,268 & 9,297 \\
\hline 1-4 Deaths & 12 & 14 & 1 & & 427 & 25,995 & 21 & 25 & 1 & 827 & 11,112 \\
\hline 5-14 Deaths & 8 & 9 & 1 & & 230 & 25,980 & 13 & 15 & 1 & 419 & 11,110 \\
\hline Adult Deaths & 193 & 206 & 1 & & 3,136 & 21,130 & 264 & 336 & 4 & 6,428 & 9,284 \\
\hline Observations & 3028 & & & & & & 12770 & & & & \\
\hline & Pan & $\mathrm{C:} \mathrm{F}$ & Percen & at of & f Deat & ths fron & n Infect & tious Di & isease & & \\
\hline & & & & No $\mathrm{H}$ & $\mathrm{HD}$ & & & & $\mathrm{HD}$ & & \\
\hline & & lean & SD & Min & $\mathrm{Ma}$ & $\mathrm{N}$ & Mea & $\mathrm{SD}$ & Min & Max & $\mathrm{N}$ \\
\hline County & & & & & & & & & & & \\
\hline$\%$ Deaths & & 19 & 9 & 1 & 58 & 20,1 & 20 & 11 & 0 & 79 & 8,219 \\
\hline$\%$ Deaths (with & & 30 & 13 & 3 & 91 & 20,2 & 33 & 15 & 3 & 104 & 8,273 \\
\hline State & & & & & & & & & & & \\
\hline$\%$ Deaths & & 18 & 6 & 7 & 49 & 30,2 & 74 & 6 & 7 & 49 & 12,715 \\
\hline \% Deaths(with T & & 26 & 8 & 10 & 58 & 30,2 & 74 & 8 & 10 & 58 & 12,715 \\
\hline & & anel & $\mathrm{D}: \mathrm{S}$ & umn & mary & Statisti & ics for $C$ & Controls & & & \\
\hline & & & & & No & HD & & & & $\mathrm{HD}$ & \\
\hline & & & Mea & & $\mathrm{SD}$ & Min & Max & Mean & $\mathrm{SD}$ & Min & Max \\
\hline$\%$ HH Marrie & & & 82 & & 8 & 0 & 100 & 83 & 6 & 33 & 100 \\
\hline HH Head Age & & & 46 & & 3 & 27 & 60 & 45 & 3 & 28 & 56 \\
\hline$\% \mathrm{HH}$ on Far & & & 50 & & 20 & 0 & 100 & 52 & 20 & 0 & 100 \\
\hline$\%$ HH Multi- & enera & ion & 73 & & 10 & 0 & 100 & 75 & 9 & 35 & 100 \\
\hline$\%$ HH Female & & & 10 & & 5 & 0 & 50 & 10 & 5 & 0 & 35 \\
\hline$\%$ Cannot Re & d or & rite & 16 & & 10 & 0 & 52 & 16 & 9 & 0 & 50 \\
\hline$\%$ Foreign & & & 7 & & 8 & 0 & 76 & 4 & 6 & 0 & 49 \\
\hline$\%$ Black & & & 8 & & 16 & 0 & 97 & 17 & 22 & 0 & 96 \\
\hline Log of Popula & ion & & 10 & & 1 & 5 & 13 & 10 & 1 & 7 & 13 \\
\hline$\%$ Urban & & & 20 & & 24 & 0 & 100 & 25 & 25 & 0 & 98 \\
\hline Land Density & & & 10 & & 39 & 0 & 1,717 & 3 & 6 & 0 & 150 \\
\hline Log of Crop & alue & & 15 & & 1 & 2 & 18 & 15 & 1 & 10 & 18 \\
\hline Log of Farm & alue & & 4 & & 1 & 0 & 8 & 4 & 1 & 1 & 7 \\
\hline Observations & & & 3028 & & & & & 12770 & & & \\
\hline
\end{tabular}

Notes: The top panel shows the summary statistics for the health investment data, the middle two panels show the mortality data, and the last panel shows the summary statistics for included controls. In Panel A, population shows a minimum of zero as a result of being in thousands, the lowest population in the sample is 165 individuals. Data sourced from U.S. Public Health Bulletin 222, US Vital Statistics, US Census Data, and US Farm Land Value data. 
Figure IV: County Health Department Characteristics Years 1910-1933
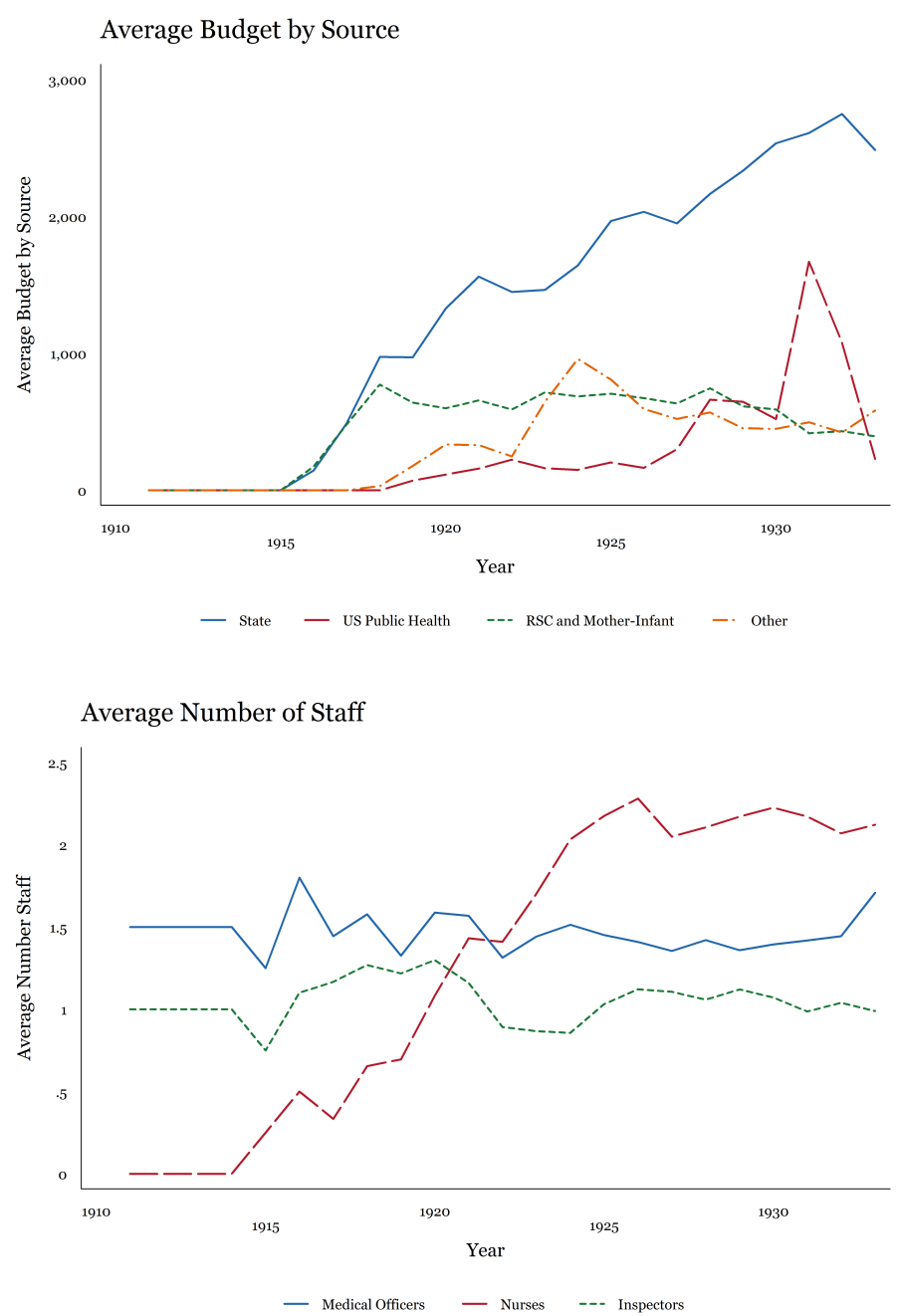

Notes: The first graph display the average amount contributed from the external sources, excluding internal funding from county. The second graph shows the average number of staff employed. Data sourced from U.S. Public Health Bulletin 222 . 
Figure V: Main Mortality Measures

Overall Mortality

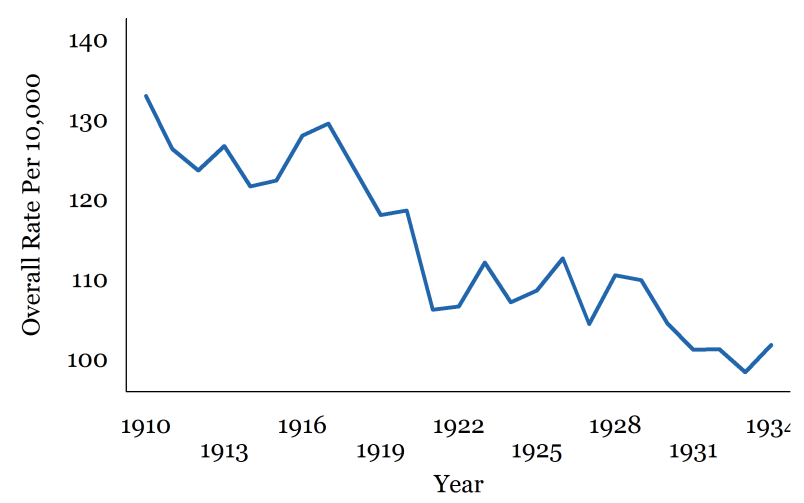

Stillbirth Rate

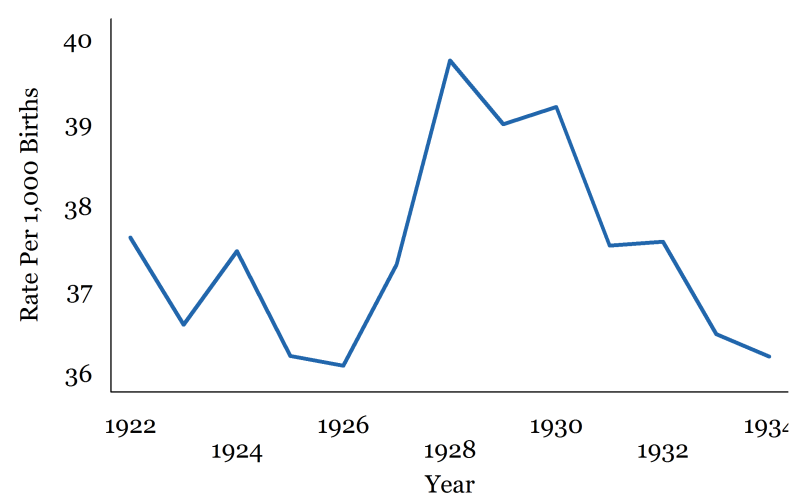

Infant Mortality

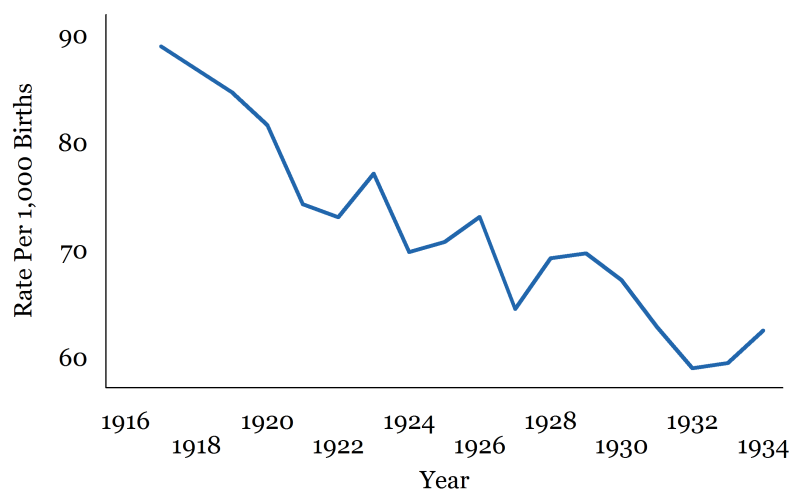

Child Mortality

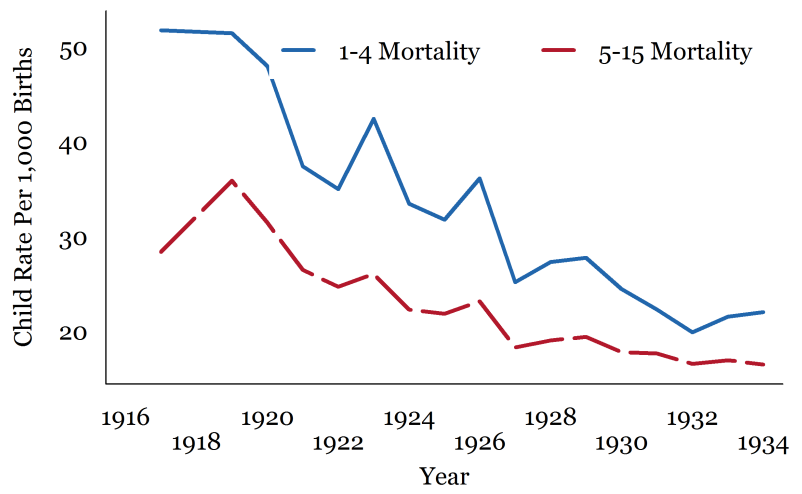

Note: Data source from US Vital Statistics. Crude mortality is defined per 10,000. Infant mortality, stillbirths, and child mortality are defined per 1,000 births. 1918 is excluded from figure. For a graph with 1918 included see Figure A.5. 
Figure VI: Distribution of Mortality, Overall and Infant

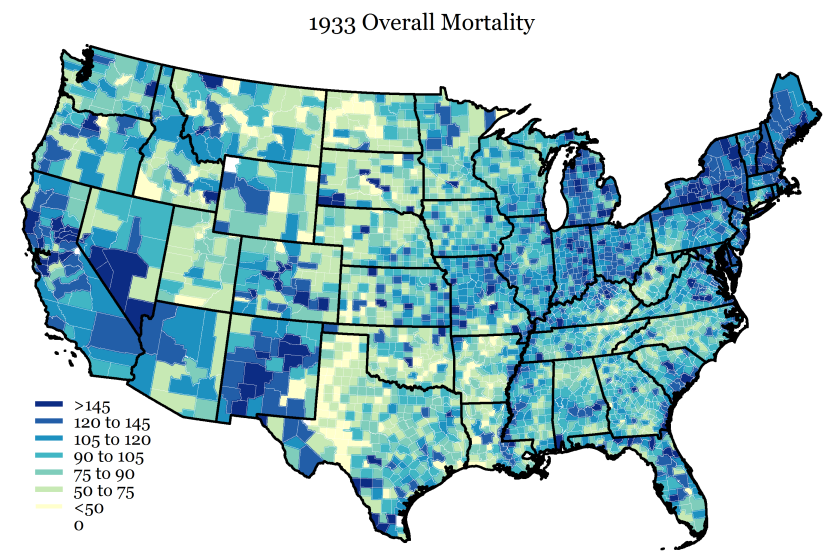

1933 Infant Mortality

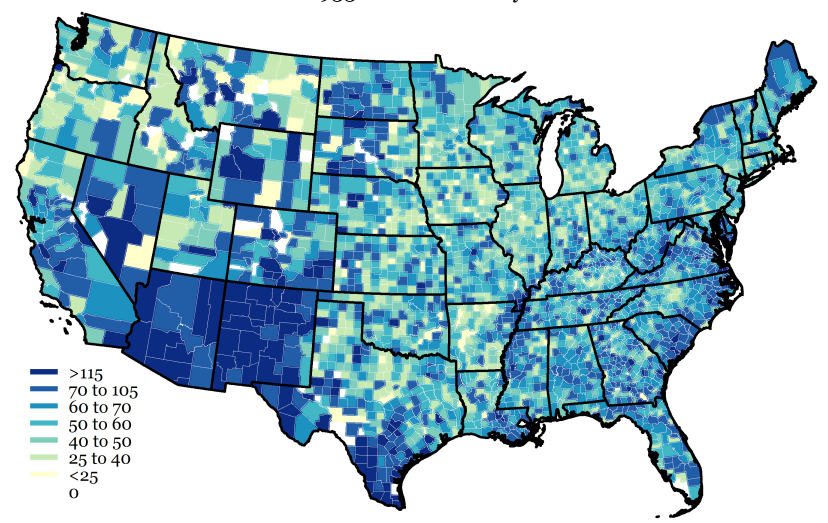

Notes: Overall mortality is the rate per 10,000 individuals. Infant mortality is the rate is per 1,000 births. Data sourced from US Vital Statistics for year 1933. 


\section{Result Tables}

Table 3: Baseline Effect of CHD on Mortality

Panel A: Mortality

\begin{tabular}{|c|c|c|c|c|c|c|c|c|c|}
\hline & \multicolumn{3}{|c|}{ Crude } & \multicolumn{3}{|c|}{ Infant } & \multicolumn{3}{|c|}{ Stillbirths } \\
\hline & (1) & (2) & (3) & (4) & (5) & (6) & (7) & (8) & (9) \\
\hline $\mathrm{N}$ & 43,038 & 42,801 & 42,800 & 30,438 & 30,297 & 30,287 & 24,682 & 24,566 & 24,541 \\
\hline County Controls & & $X$ & $X$ & & $X$ & $X$ & & $X$ & $X$ \\
\hline County Fixed Effects & $X$ & $X$ & $X$ & $X$ & $X$ & $X$ & $X$ & $X$ & $X$ \\
\hline
\end{tabular}

Panel B: Adjusted Mortality

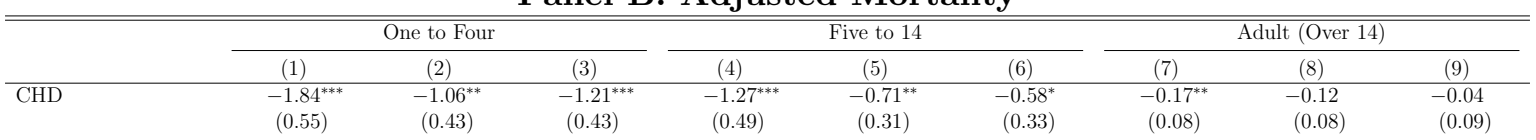

\begin{tabular}{lrrrrrrrr}
\hline $\mathrm{N}$ & 30,625 & 30,462 & 30,461 & 30,608 & 30,445 & 30,444 & 30,414 & 30,274 \\
County Controls & & $X$ & $X$ & & $X$ & $X$ & $X 0,265$ & $X$ \\
County Fixed Effects & $X$ & $X$ & $X$ & $X$ & $X$ & $X$ & $X$ & $X$ \\
Year Fixed Effects & $X$ & $X$ & $X$ & $X$ & $X$ & $X$ & $X$ & $X$ \\
State Time Trend & & & $X$ & & & $X$ & $X$ \\
\hline
\end{tabular}

Notes: Reported coefficient estimates of $\beta$ from specification (3.1). CHD is a binary variable and equals one if a CHD is present in time

$t-1$ and zero otherwise. Crude and adult mortality are per 10,000 individuals. Infant and child mortality are per 1,000 births. Robust standard errors clustered at the county-level with significance levels are at 10,5 , and 1 percent levels. Data sourced from U.S. Public Health Bulletin 222, US Vital Statistics, US Census Data, and US Farm Land Value data. 
Table 4: Summary Statistics, by Race

\begin{tabular}{|c|c|c|c|c|c|c|c|c|c|c|}
\hline & \multicolumn{5}{|c|}{ No HD } & \multicolumn{5}{|c|}{ HD } \\
\hline & Mean & $\mathrm{SD}$ & Min & $\operatorname{Max}$ & $\mathrm{N}$ & Mean & $\mathrm{SD}$ & Min & $\operatorname{Max}$ & $\mathrm{N}$ \\
\hline \multicolumn{11}{|l|}{ Black } \\
\hline Deaths & 83 & 75 & 1 & 719 & 5,123 & 161 & 173 & 1 & 2,348 & 4,268 \\
\hline Population (K) & 7 & 5 & 0 & 39 & 5,142 & 11 & 11 & 0 & 163 & 4,233 \\
\hline Infant Deaths & 14 & 15 & 1 & 169 & 4,717 & 28 & 32 & 1 & 365 & 4,124 \\
\hline Births & 151 & 137 & 1 & 1,222 & 4,873 & 289 & 318 & 2 & 3,961 & 4,154 \\
\hline \multicolumn{11}{|l|}{ White } \\
\hline Deaths & 110 & 98 & 1 & 1,163 & 5,146 & 186 & 191 & 3 & 4,402 & 4,269 \\
\hline Population (K) & 12 & 10 & 0 & 110 & 5,142 & 20 & 18 & 1 & 390 & 4,235 \\
\hline Infant Deaths & 17 & 16 & 1 & 212 & 4,804 & 30 & 27 & 1 & 358 & 4,133 \\
\hline Births & 265 & 226 & 1 & 2,422 & 4,910 & 443 & 367 & 4 & 4,262 & 4,156 \\
\hline Observations & 5678 & & & & & 4788 & & & & \\
\hline
\end{tabular}

Notes: Data sourced from US Vital Statistics. 
Table 5: Effect of CHD on Mortality by Race

Panel A: Crude Mortality, by Race

\begin{tabular}{lccccccc}
\hline \hline & \multicolumn{3}{c}{ Black } & & \multicolumn{3}{c}{ White } \\
\cline { 2 - 4 } \cline { 6 - 8 } & $(1)$ & $(2)$ & $(3)$ & & $(4)$ & $(5)$ & $(6)$ \\
\hline CHD & $-3.32^{*}$ & -2.33 & -2.10 & & 0.25 & 1.00 & 0.76 \\
& $(1.94)$ & $(1.88)$ & $(1.93)$ & & $(2.01)$ & $(2.00)$ & $(2.12)$ \\
& & & & & & & \\
\hline $\mathrm{N}$ & 9,303 & 9,263 & 9,254 & & 9,323 & 9,278 & 9,269 \\
County Controls & & $X$ & $X$ & & & $X$ & $X$ \\
County Fixed Effects & $X$ & $X$ & $X$ & & $X$ & $X$ & $X$ \\
Year Fixed Effects & $X$ & $X$ & $X$ & & $X$ & $X$ & $X$ \\
State Time Trend & & & $X$ & & & & $X$ \\
\hline \hline
\end{tabular}

Panel B: Infant Mortality, by Race

\begin{tabular}{|c|c|c|c|c|c|c|}
\hline & \multicolumn{3}{|c|}{ Black } & \multicolumn{3}{|c|}{ White } \\
\hline & (1) & $(2)$ & (3) & (4) & $(5)$ & (6) \\
\hline CHD & $\begin{array}{c}-13.84^{* * *} \\
(3.97)\end{array}$ & $\begin{array}{c}-14.76^{* * *} \\
(3.72)\end{array}$ & $\begin{array}{c}-8.48^{* * *} \\
(2.43)\end{array}$ & $\begin{array}{c}-2.36^{* *} \\
(1.15)\end{array}$ & $\begin{array}{c}-2.43^{* *} \\
(1.10)\end{array}$ & $\begin{array}{c}-1.43 \\
(1.07)\end{array}$ \\
\hline $\mathrm{N}$ & 8,836 & 8,803 & 8,779 & 8,937 & 8,899 & 8,877 \\
\hline County Controls & & $X$ & $X$ & & $X$ & $X$ \\
\hline County Fixed Effects & $X$ & $X$ & $X$ & $X$ & $X$ & $X$ \\
\hline Year Fixed Effects & $X$ & $X$ & $X$ & $X$ & $X$ & $X$ \\
\hline State Time Trend & & & $X$ & & & $X$ \\
\hline
\end{tabular}

Notes: Reported coefficient estimates of $\beta$ from specification (3.1). CHD is a binary variable and equals one if a CHD is present in time $t-1$ and zero otherwise. Crude and adult mortality are per 10,000 individuals. Infant and child mortality are per 1,000 births. Robust standard errors clustered at the county-level with significance levels are at 10, 5, and 1 percent levels. Data sourced from U.S. Public Health Bulletin 222, US Vital Statistics, US Census Data, and US Farm Land Value data. 
Table 6: Effect of Funding Variation on Mortality

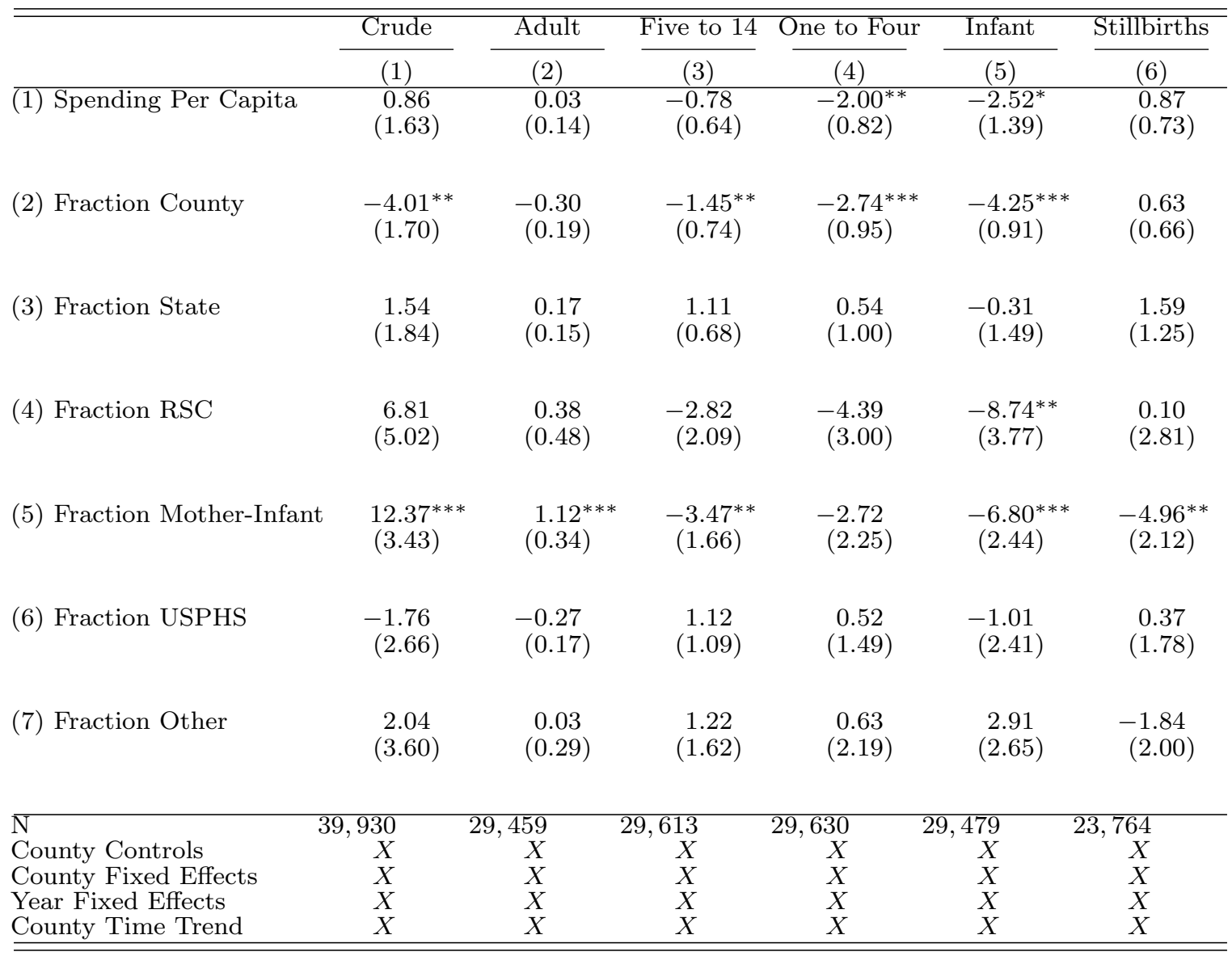

Notes: Reported coefficient estimates of $\beta$ from specification (3.1) and each row is a separate estimation on mortality at $t$. Fraction of each category is the budget amount funded by source, divided by the total budget at time $t-1$. Mother-Infant is the sum of the budget from the Sheppard-Towner Act plus other individual sources such as the Children's Fund of Michigan. Other is defined as in the original document. Crude and adult mortality are per 10,000 individuals. Infant and child mortality are per 1,000 births. Robust standard errors clustered at the county-level with significance levels are at 10, 5, and 1 percent levels. Data sourced from U.S. Public Health Bulletin 222, US Vital Statistics, US Census Data, and US Farm Land Value data. 
Table 7: Controlling for Pre-treatment Infectious Disease at the State Level

\begin{tabular}{|c|c|c|c|c|c|c|}
\hline & Crude & Adult & Five to 14 & One to Four & Infant & Stillbirths \\
\hline & (1) & (2) & (3) & (4) & (5) & (6) \\
\hline (1) CHD x Acute Infectious & $\begin{array}{c}-7.16 \\
(4.63)\end{array}$ & $\begin{array}{c}-0.55 \\
(0.55)\end{array}$ & $\begin{array}{c}-3.62^{* *} \\
(1.84)\end{array}$ & $\begin{array}{c}-7.33^{* * *} \\
(2.52)\end{array}$ & $\begin{array}{c}-11.30^{* * *} \\
(2.58)\end{array}$ & $\begin{array}{c}0.58 \\
(2.29)\end{array}$ \\
\hline (2) CHD x All Infectious & $\begin{array}{c}-4.33 \\
(3.07)\end{array}$ & $\begin{array}{c}-0.31 \\
(0.35)\end{array}$ & $\begin{array}{c}-2.33^{*} \\
(1.24)\end{array}$ & $\begin{array}{c}-4.81^{* * *} \\
(1.71)\end{array}$ & $\begin{array}{c}-7.59^{* * *} \\
(1.86)\end{array}$ & $\begin{array}{c}0.38 \\
(1.61)\end{array}$ \\
\hline $\mathrm{N}$ & 38,977 & 28,594 & 28,747 & 28,764 & 28,614 & 22,931 \\
\hline CHD X Year & 4,121 & 3,928 & 3,931 & 3,932 & 3,929 & 3,764 \\
\hline Mean Acute Infectious & 0.22 & 0.22 & 0.22 & 0.22 & 0.22 & 0.22 \\
\hline Mean All Infectious & 0.31 & 0.31 & 0.31 & 0.31 & 0.31 & 0.31 \\
\hline County Controls & $X$ & $X$ & $X$ & $X$ & $X$ & $X$ \\
\hline County Fixed Effects & $X$ & $X$ & $X$ & $X$ & $X$ & $X$ \\
\hline Year Fixed Effects & $X$ & $X$ & $X$ & $X$ & $X$ & $X$ \\
\hline State Time Trend & $X$ & $X$ & $X$ & $X$ & $X$ & $X$ \\
\hline
\end{tabular}

Notes: Reported coefficient estimates of $\beta$ from specification (3.3) and each row is a separate estimation on mortality at $t$. Acute infectious diseases include typhoid, smallpox, malaria, measles, scarlet fever, whooping cough, diphtheria and/or croup, influenza, pneumonia, meningitis, and diarrhea for children under two. All infectious disease includes the previous acute with the addition of TB. Crude and adult mortality are per 10,000 individuals. Infant and child mortality are per 1,000 births. Robust standard errors clustered at the county-level with significance levels are at 10, 5, and 1 percent levels. Data sourced from U.S. Public Health Bulletin 222, US Vital Statistics, US Census Data, and US Farm Land Value data. 
Table 8: Pre-treatment Conditions and CHD Location

Panel A: State-Level Infectious Disease

\begin{tabular}{lc}
\hline \hline & HD \\
\cline { 2 - 2 } & $(1)$ \\
\hline Acute Infectious & $1.164^{* * *}$ \\
& $(0.038)$ \\
& \\
\hline $\mathrm{N}$ & 2,519 \\
County Controls & $X$ \\
Region Fixed Effects & $X$ \\
\hline \hline
\end{tabular}

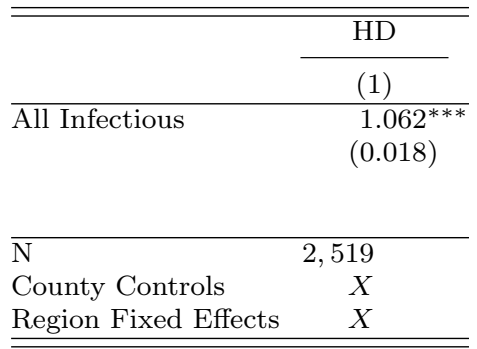

Panel B: County-Level Infectious Disease

\begin{tabular}{lc}
\hline \hline & HD \\
\cline { 2 - 2 } & $(1)$ \\
\hline Acute Infectious & $1.034^{* *}$ \\
& $(0.015)$ \\
& \\
\hline $\mathrm{N}$ & 1,171 \\
County Controls & $X$ \\
State Fixed Effects & $X$ \\
\hline \hline
\end{tabular}

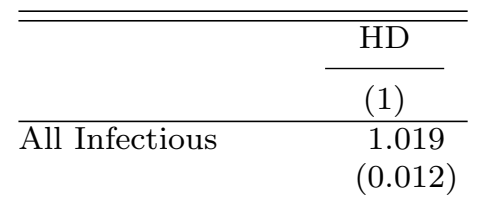

\begin{tabular}{lr}
\hline $\mathrm{N}$ & 1,178 \\
County Controls & $X$ \\
State Fixed Effects & $X$ \\
\hline
\end{tabular}

Panel C: Individual Mortality Rates

\begin{tabular}{cc}
\hline \hline & HD \\
\cline { 2 - 2 } & $(1)$ \\
\hline Mortality & 0.997 \\
& $(0.003)$
\end{tabular}

\begin{tabular}{lc}
\hline \hline & $\mathrm{HD}$ \\
\cline { 2 - 2 } & $(1)$ \\
\hline Infant Mortality & 1.002 \\
& $(0.003)$
\end{tabular}

\begin{tabular}{lr}
\hline $\mathrm{N}$ & 2,495 \\
County Controls & $X$ \\
State Fixed Effects & $X$ \\
\hline \hline
\end{tabular}

\begin{tabular}{lr}
\hline $\mathrm{N}$ & 2,485 \\
County Controls & $X$ \\
State Fixed Effects & $X$ \\
\hline \hline
\end{tabular}

Notes: Reported odds rations from a logit regression estimating the likelihood of implementing a CHD from (5.1). Acute infectious diseases include typhoid, smallpox, malaria, measles, scarlet fever, whooping cough, diphtheria and/or croup, influenza, pneumonia, meningitis, and diarrhea for children under two. All infectious disease includes the previous acute with the addition of TB. Robust standard errors clustered at the county-level with significance levels are at 10,5, and 1 percent levels. Data sourced from U.S. Public Health Bulletin 222, US Vital Statistics, US Census Data, and US Farm Land Value data. 


\section{Robustness Tables}

Figure VII: Distribution of Mortality, by Cause

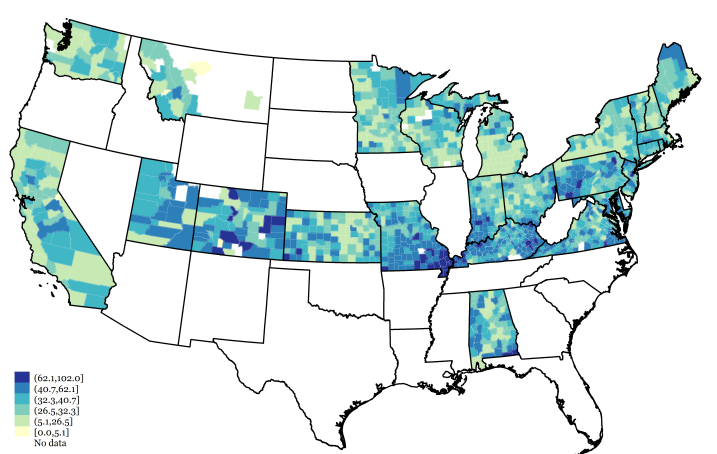

County Infectious 1912 and 1914

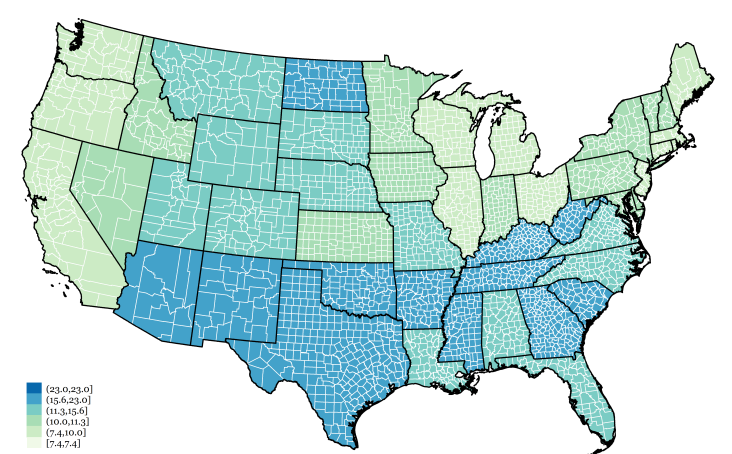

State Infectious 1933

Note: Data source from US Vital Statistics. 
Table 9: Pre-treatment Infectious Disease at the County Level

\begin{tabular}{|c|c|c|c|}
\hline & Crude & Infant & Stillbirths \\
\hline & (1) & (2) & (3) \\
\hline (1) CHD x Acute Infectious & $\begin{array}{r}-12.10^{*} \\
(7.25)\end{array}$ & $\begin{array}{c}-7.83^{* *} \\
(3.05)\end{array}$ & $\begin{array}{c}1.44 \\
(2.34)\end{array}$ \\
\hline (2) CHD x All Infectious & $\begin{array}{c}-5.61 \\
(3.81)\end{array}$ & $\begin{array}{c}-3.98^{* *} \\
(1.91)\end{array}$ & $\begin{array}{c}0.95 \\
(1.58)\end{array}$ \\
\hline $\mathrm{N}$ & 27,165 & 18,579 & 13,876 \\
\hline CHD X Year & 2,529 & 2,423 & 2,330 \\
\hline Mean Acute Infectious & 0.20 & 0.20 & 0.20 \\
\hline Mean All Infectious & 0.33 & 0.33 & 0.33 \\
\hline County Controls & $X$ & $X$ & $X$ \\
\hline County Fixed Effects & $X$ & $X$ & $X$ \\
\hline Year Fixed Effects & $X$ & $X$ & $X$ \\
\hline State Time Trend & $X$ & $X$ & $X$ \\
\hline
\end{tabular}

Notes: Reported coefficient estimates of $\beta$ from specification (3.3) and each row is a separate estimation on mortality at $t$. Acute infectious diseases include typhoid, smallpox, malaria, measles, scarlet fever, whooping cough, diphtheria and/or croup, influenza, pneumonia, meningitis, and diarrhea for children under two. All infectious disease includes the previous acute with the addition of TB. Crude mortality is per 10,000 individuals. Infant mortality is per 1,000 births. Robust standard errors clustered at the county-level with significance levels are at 10,5 , and 1 percent levels. Data sourced from U.S. Public Health Bulletin 222, US Vital Statistics, US Census Data, and US Farm Land Value data. 
Table 10: Pre-treatment Infectious Disease Check

\begin{tabular}{|c|c|c|c|c|c|c|}
\hline & Crude & Adult & Five to 14 & One to Four & Infant & Stillbirths \\
\hline & $(1)$ & $(2)$ & (3) & (4) & $(5)$ & (6) \\
\hline (1) CHD x Acute Infectious & $\begin{array}{c}-5.67 \\
(4.21)\end{array}$ & $\begin{array}{c}-0.35 \\
(0.45)\end{array}$ & $\begin{array}{c}-2.81^{*} \\
(1.60)\end{array}$ & $\begin{array}{c}-6.07^{* * *} \\
(2.23)\end{array}$ & $\begin{array}{c}-10.38^{* * *} \\
(2.56)\end{array}$ & $\begin{array}{c}0.46 \\
(2.21)\end{array}$ \\
\hline (2) CHD x All Infectious & $\begin{array}{c}-3.52 \\
(2.83)\end{array}$ & $\begin{array}{c}-0.20 \\
(0.29)\end{array}$ & $\begin{array}{r}-1.88^{*} \\
(1.10)\end{array}$ & $\begin{array}{c}-4.09^{* * *} \\
(1.54)\end{array}$ & $\begin{array}{c}-6.98^{* * *} \\
(1.82)\end{array}$ & $\begin{array}{c}0.32 \\
(1.55)\end{array}$ \\
\hline $\mathrm{N}$ & 38,977 & 28,594 & 28,747 & 28,764 & 28,614 & 22,931 \\
\hline CHD X Year & 4,121 & 3,928 & 3,931 & 3,932 & 3,929 & 3,764 \\
\hline Mean Acute Infectious & 0.19 & 0.19 & 0.19 & 0.19 & 0.19 & 0.19 \\
\hline Mean All Infectious & 0.27 & 0.27 & 0.27 & 0.27 & 0.27 & 0.27 \\
\hline County Controls & $X$ & $X$ & $X$ & $X$ & $X$ & $X$ \\
\hline County Fixed Effects & $X$ & $X$ & $X$ & $X$ & $X$ & $X$ \\
\hline Year Fixed Effects & $X$ & $X$ & $X$ & $X$ & $X$ & $X$ \\
\hline State Time Trend & $X$ & $X$ & $X$ & $X$ & $X$ & $X$ \\
\hline
\end{tabular}

Notes: Reported coefficient estimates of $\beta$ from specification (3.3) and each row is a separate estimation on mortality at $t$. Acute infectious diseases include typhoid, smallpox, malaria, measles, scarlet fever, whooping cough, diphtheria and/or croup, influenza, pneumonia, meningitis, and diarrhea for children under two. All infectious disease includes the previous acute with the addition of TB. Crude mortality is per 10,000 individuals. Infant mortality is per 1,000 births. Robust standard errors clustered at the county-level with significance levels are at 10,5, and 1 percent levels. Data sourced from U.S. Public Health Bulletin 222, US Vital Statistics, US Census Data, and US Farm Land Value data. 
Table 11: Distributed Lag Model

Panel A: Lags

\begin{tabular}{|c|c|c|c|c|c|c|}
\hline & \multicolumn{3}{|c|}{ Crude } & \multicolumn{3}{|c|}{ Infant } \\
\hline & (1) & $(2)$ & (3) & (4) & (5) & $(6)$ \\
\hline$\overline{\mathrm{CHD}}$ & $\begin{array}{l}1.58^{* * *} \\
(0.59)\end{array}$ & $\begin{array}{l}1.25^{* *} \\
(0.60)\end{array}$ & $\begin{array}{c}1.02^{*} \\
(0.61)\end{array}$ & $\begin{array}{c}0.49 \\
(0.61)\end{array}$ & $\begin{array}{c}0.39 \\
(0.62)\end{array}$ & $\begin{array}{c}0.44 \\
(0.63)\end{array}$ \\
\hline L1.CHD & $\begin{array}{c}-0.90 \\
(0.60)\end{array}$ & $\begin{array}{c}-0.64 \\
(0.60)\end{array}$ & $\begin{array}{c}-0.56 \\
(0.60)\end{array}$ & $\begin{array}{c}-1.07 \\
(0.73)\end{array}$ & $\begin{array}{c}-1.04 \\
(0.73)\end{array}$ & $\begin{array}{c}-1.04 \\
(0.73)\end{array}$ \\
\hline L2.CHD & $\begin{array}{r}-1.02^{*} \\
(0.60)\end{array}$ & $\begin{array}{r}-1.16^{*} \\
(0.60)\end{array}$ & $\begin{array}{r}-1.07^{*} \\
(0.59)\end{array}$ & $\begin{array}{c}-2.04^{* *} \\
(0.80)\end{array}$ & $\begin{array}{c}-2.09^{* * *} \\
(0.80)\end{array}$ & $\begin{array}{c}-2.13^{* * *} \\
(0.80)\end{array}$ \\
\hline L3.CHD & $\begin{array}{c}-2.59^{* * *} \\
(0.69)\end{array}$ & $\begin{array}{c}-0.24 \\
(0.54)\end{array}$ & $\begin{array}{c}-0.11 \\
(0.54)\end{array}$ & $\begin{array}{c}0.02 \\
(0.69)\end{array}$ & $\begin{array}{c}0.88 \\
(0.80)\end{array}$ & $\begin{array}{c}0.93 \\
(0.80)\end{array}$ \\
\hline L4.CHD & & $\begin{array}{c}-1.23^{* *} \\
(0.49)\end{array}$ & $\begin{array}{c}-1.42^{* * *} \\
(0.50)\end{array}$ & & $\begin{array}{r}-1.00 \\
(0.77)\end{array}$ & $\begin{array}{r}-0.96 \\
(0.77)\end{array}$ \\
\hline L5.CHD & & $\begin{array}{c}-2.68^{* * *} \\
(0.72)\end{array}$ & $\begin{array}{c}-1.30^{* *} \\
(0.52)\end{array}$ & & $\begin{array}{r}-0.27 \\
(0.66)\end{array}$ & $\begin{array}{r}-1.17^{*} \\
(0.70)\end{array}$ \\
\hline L6.CHD & & & $\begin{array}{c}0.45 \\
(0.57)\end{array}$ & & & $\begin{array}{l}1.77^{* *} \\
(0.76)\end{array}$ \\
\hline L7.CHD & & & $\begin{array}{c}-3.62^{* * *} \\
(0.91)\end{array}$ & & & $\begin{array}{c}-0.80 \\
(0.75)\end{array}$ \\
\hline
\end{tabular}

\begin{tabular}{lrrrrrr}
\hline $\mathrm{N}$ & 42,801 & 42,801 & 42,801 & 30,297 & 30,297 & 30,297 \\
County Controls & $X$ & $X$ & $X$ & $X$ & $X$ & $X$ \\
County Fixed Effects & $X$ & $X$ & $X$ & $X$ & $X$ & $X$ \\
Year Fixed Effects & $X$ & $X$ & $X$ & $X$ & $X$ & $X$ \\
\hline \hline
\end{tabular}

Panel B: Leads

\begin{tabular}{lccccccc}
\hline \hline & \multicolumn{3}{c}{ Crude } & & \multicolumn{3}{c}{ Infant } \\
\cline { 2 - 3 } \cline { 6 - 8 } & $(1)$ & $(2)$ & $(3)$ & & $(4)$ & $(5)$ & $(6)$ \\
\hline F.CHD & 1.13 & -1.24 & -1.00 & & 0.72 & -1.09 & -1.20 \\
& $(0.72)$ & $(0.98)$ & $(1.11)$ & & $(0.55)$ & $(0.81)$ & $(0.93)$
\end{tabular}

\begin{tabular}{|c|c|c|c|c|}
\hline F2.CHD & $\begin{array}{c}0.51 \\
(0.90)\end{array}$ & $\begin{array}{c}1.83^{*} \\
(1.02)\end{array}$ & $\begin{array}{c}0.96 \\
(0.84)\end{array}$ & $\begin{array}{c}1.43 \\
(0.95)\end{array}$ \\
\hline F3.CHD & $\begin{array}{l}1.56^{* * *} \\
(0.57)\end{array}$ & $\begin{array}{c}0.57 \\
(0.70)\end{array}$ & $\begin{array}{c}0.71 \\
(0.65)\end{array}$ & $\begin{array}{c}0.05 \\
(0.94)\end{array}$ \\
\hline F4.CHD & & $\begin{array}{r}-0.45 \\
(0.67)\end{array}$ & & $\begin{array}{r}-1.77^{*} \\
(0.97)\end{array}$ \\
\hline F5.CHD & & $\begin{array}{c}-1.62^{* * *} \\
(0.59)\end{array}$ & & $\begin{array}{c}0.59 \\
(0.67)\end{array}$ \\
\hline
\end{tabular}

\begin{tabular}{lrrrrrr}
\hline $\mathrm{N}$ & 40,165 & 35,123 & 30,549 & 27,809 & 23,058 & 18,646 \\
County Controls & $X$ & $X$ & $X$ & $X$ & $X$ & $X$ \\
County Fixed Effects & $X$ & $X$ & $X$ & $X$ & $X$ & $X$ \\
Year Fixed Effects & $X$ & $X$ & $X$ & $X$ & $X$ & $X$ \\
\hline \hline
\end{tabular}

Notes: Reported coefficient estimates of $\beta$ from specification (6.1) on mortality at $t$. Panel A shows the lags and Panel B shows the leads. Crude mortality is per 10,000 deaths. Infant mortality is per 1,000 births. Robust standard errors clustered at the county-level. Significance levels are at 10, 5, and 1 percent levels. Data sourced from U.S. Public Health Bulletin 222, US Vital Statistics, US Census Data, and US Farm Land Value data. 
Table 12: Limited Estimation Period

Panel A: Two Years Post

\begin{tabular}{|c|c|c|c|c|c|}
\hline & Crude & Adult & Five to 14 & One to Four & Infant \\
\hline & (1) & $(2)$ & $(3)$ & (4) & $(5)$ \\
\hline L1.CHD & $\begin{array}{c}-0.41 \\
(0.93)\end{array}$ & $\begin{array}{c}-0.05 \\
(0.09)\end{array}$ & $\begin{array}{r}-0.55^{*} \\
(0.32)\end{array}$ & $\begin{array}{r}-0.83^{*} \\
(0.43)\end{array}$ & $\begin{array}{c}-1.74^{* * *} \\
(0.67)\end{array}$ \\
\hline $\mathrm{N}$ & 31,247 & 24,305 & 24,454 & 24,471 & 24,325 \\
\hline County Controls & $X$ & $X$ & $X$ & $X$ & $X$ \\
\hline County Fixed Effects & $X$ & $X$ & $X$ & $X$ & $X$ \\
\hline Year Fixed Effects & $X$ & $X$ & $X$ & $X$ & $X$ \\
\hline State Time Trend & $X$ & $X$ & $X$ & $X$ & $X$ \\
\hline
\end{tabular}

Panel B: 1920s and Balanced Panel

\begin{tabular}{|c|c|c|c|c|c|}
\hline & Crude & Adult & Five to 14 & One to Four & Infant \\
\hline & (1) & $(2)$ & (3) & (4) & (5) \\
\hline CHD & $\begin{array}{c}-0.76 \\
(1.21)\end{array}$ & $\begin{array}{c}-0.07 \\
(0.11)\end{array}$ & $\begin{array}{c}-0.45 \\
(0.39)\end{array}$ & $\begin{array}{r}-0.91^{*} \\
(0.53)\end{array}$ & $\begin{array}{c}-1.72^{* * *} \\
(0.62)\end{array}$ \\
\hline $\mathrm{N}$ & 23,384 & 20,799 & 20,901 & 20,901 & 20,804 \\
\hline County Controls & $X$ & $X$ & $X$ & $X$ & $X$ \\
\hline County Fixed Effects & $X$ & $X$ & $X$ & $X$ & $X$ \\
\hline Year Fixed Effects & $X$ & $X$ & $X$ & $X$ & $X$ \\
\hline State Time Trend & $X$ & $X$ & $X$ & $X$ & $X$ \\
\hline
\end{tabular}

Notes: Reported coefficient estimates of $\beta$ from specification (3.1) on mortality at $t$. Panel A shows the results with restriction (6.2) at two years post implementation. Panel B is a balanced panel of states estimated from 1920-1934. Health Department is a binary variable and equals one if a CHD is present in time $t-1$ and zero otherwise. Crude and adult mortality are per 10,000 individuals. Infant and child mortality are per 1,000 births. Robust standard errors clustered at the county-level. Significance levels are at 10, 5, and 1 percent levels. Data sourced from U.S. Public Health Bulletin 222, US Vital Statistics, US Census Data, and US Farm Land Value data. 
Table 13: Modified Identification

Panel A: Restricted to Infant Sample

\begin{tabular}{|c|c|c|c|c|c|}
\hline & \multirow{2}{*}{$\begin{array}{c}\text { Crude } \\
(1)\end{array}$} & \multirow{2}{*}{$\begin{array}{c}\text { Adult } \\
(2)\end{array}$} & \multicolumn{2}{|c|}{ Five to 14 One to Four } & \multirow{2}{*}{$\begin{array}{c}\text { Infant } \\
(5)\end{array}$} \\
\hline & & & $(3)$ & (4) & \\
\hline L1.CHD & $\begin{array}{c}-0.45 \\
(0.98)\end{array}$ & $\begin{array}{c}-0.04 \\
(0.09)\end{array}$ & $\begin{array}{r}-0.58^{*} \\
(0.33)\end{array}$ & $\begin{array}{c}-1.21^{* * *} \\
(0.43)\end{array}$ & $\begin{array}{c}-2.36^{* *} \\
(1.01)\end{array}$ \\
\hline
\end{tabular}

\begin{tabular}{lrrrrr}
\hline N & 30,285 & 30,265 & 30,444 & 30,461 & 30,461 \\
County Controls & $X$ & $X$ & $X$ & $X$ & $X$ \\
County Fixed Effects & $X$ & $X$ & $X$ & $X$ & $X$ \\
Year Fixed Effects & $X$ & $X$ & $X$ & $X$ & $X$ \\
State Time Trend & $X$ & $X$ & $X$ & $X$ & $X$ \\
\hline
\end{tabular}

\begin{tabular}{|c|c|c|c|c|c|}
\hline \multicolumn{6}{|c|}{ Panel B: Replacing Outcome $-\log \left(m_{j s t}\right)$} \\
\hline & Crude & "Adult & Five to 14 & ne to Four & Infant \\
\hline & (1) & (2) & (3) & (4) & (5) \\
\hline L1.CHD & $\begin{array}{c}-0.00 \\
(0.01)\end{array}$ & $\begin{array}{c}0.00 \\
(0.01)\end{array}$ & $\begin{array}{c}-0.02^{* * *} \\
(0.01)\end{array}$ & $\begin{array}{c}-0.04^{* * *} \\
(0.01)\end{array}$ & $\begin{array}{c}-0.03^{* * *} \\
(0.01)\end{array}$ \\
\hline
\end{tabular}

\begin{tabular}{lrrrrr}
\hline N & 42,800 & 30,265 & 30,444 & 30,461 & 30,287 \\
County Controls & $X$ & $X$ & $X$ & $X$ & $X$ \\
County Fixed Effects & $X$ & $X$ & $X$ & $X$ & $X$ \\
Year Fixed Effects & $X$ & $X$ & $X$ & $X$ & $X$ \\
State Time Trend & $X$ & $X$ & $X$ & $X$ & $X$ \\
\hline
\end{tabular}

\begin{tabular}{|c|c|c|c|c|c|}
\hline \multicolumn{6}{|c|}{ Panel C: County Time Trends } \\
\hline & Crude & Adult & Five to 14 & ne to Four & Infant \\
\hline & (1) & $(2)$ & $(3)$ & (4) & (5) \\
\hline L1.CHD & $\begin{array}{c}0.99 \\
(0.76)\end{array}$ & $\begin{array}{c}0.02 \\
(0.09)\end{array}$ & $\begin{array}{c}-0.68^{* * *} \\
(0.26)\end{array}$ & $\begin{array}{c}-1.63^{* * *} \\
(0.36)\end{array}$ & $\begin{array}{c}-1.58^{* *} \\
(0.62)\end{array}$ \\
\hline 42 & 800 & 30,265 & 30,444 & 461 & 287 \\
\hline County Controls & $X$ & $X$ & $X$ & $X$ & $X$ \\
\hline County Fixed Effects & $X$ & $X$ & $X$ & $X$ & $X$ \\
\hline Year Fixed Effects & $X$ & $X$ & $X$ & $X$ & $X$ \\
\hline County Time Trend & $X$ & $X$ & $X$ & $X$ & $X$ \\
\hline
\end{tabular}

Panel D: Dropping Population Outliers (5\% Tails)

\begin{tabular}{|c|c|c|c|c|c|}
\hline & \multirow{2}{*}{$\begin{array}{c}\text { Crude } \\
(1)\end{array}$} & \multirow{2}{*}{$\begin{array}{c}\text { Adult } \\
(2)\end{array}$} & \multicolumn{2}{|c|}{ Five to 14 One to Four } & \multirow{2}{*}{$\begin{array}{c}\text { Infant } \\
(5)\end{array}$} \\
\hline & & & $(3)$ & (4) & \\
\hline L1.CHD & $\begin{array}{c}-0.24 \\
(0.85)\end{array}$ & $\begin{array}{c}-0.04 \\
(0.09)\end{array}$ & $\begin{array}{c}-0.29 \\
(0.26)\end{array}$ & $\begin{array}{c}-0.87^{* *} \\
(0.36)\end{array}$ & $\begin{array}{c}-1.91^{* * *} \\
(0.55)\end{array}$ \\
\hline
\end{tabular}

\begin{tabular}{lrrrrr}
\hline N & 38,582 & 27,509 & 27,528 & 27,539 & 27,522 \\
County Controls & $X$ & $X$ & $X$ & $X$ & $X$ \\
County Fixed Effects & $X$ & $X$ & $X$ & $X$ & $X$ \\
Year Fixed Effects & $X$ & $X$ & $X$ & $X$ & $X$ \\
State Time Trend & $X$ & $X$ & $X$ & $X$ & $X$ \\
\hline \hline
\end{tabular}

Notes: Reported coefficient estimate $\beta$ from specification (3.1) on mortality at $t$. Panel A shows effects on the infant sample and crude mortality adjusted to remove infant mortality, with the infant mortality measure computed at the state level. Panel B displays the logarithmic estimation. Panel C shows county time trends. Panel D displays the estimation with exclusion of exceptionally large or small counties. CHD is a binary variable and equals one if a CHD is present in time $t-1$ and zero otherwise. Crude and adult mortality are per 10,000 individuals. Infant and child mortality are per 1,000 births. Significance levels are at 10, 5, and 1 percent levels. Data sourced from U.S. Public Health Bulletin 222, US Vital Statistics, US Census Data, and US Farm Land Value data. 


\section{Bibliography}

Thomas Franklin Abercrombie. History of Public Health in Georgia, 1733-1950. Georgia Department of Public Health, 1951.

Jeanne E Abrams. Revolutionary Medicine: The Founding Fathers and Mothers in Sickness and in Health. NYU Press, 2013.

Daron Acemoglu and Simon Johnson. Disease and development: The effect of life expectancy on economic growth. Technical Report 6, 2007.

Stefania Albanesi and Claudia Olivetti. Maternal health and the baby boom. Quantitative Economics, 5(2):225-269, 2014.

Stefania Albanesi and Claudia Olivetti. Gender roles and medical progress. Journal of Political Economy, 124(3):650-695, 2016.

Marcella Alsan and Claudia Goldin. Watersheds in infant mortality: The role of effective water and sewerage infrastructure, 1880 to 1915. Technical report, National Bureau of Economic Research, 2015.

Marion E Altenderfer. Full-time public health positions in local health departments. Public Health Reports (1896-1970), pages 866-874, 1946.

Letty Anderson. Hard choices: Supplying water to new england towns. Journal of Interdisciplinary History, pages 211-234, 1984.

DB Armstrong, CV Chapin, H Emerson, AW Freeman, WH Frost, LR Thompson, C-EA Winslow, and LI Dublin. Report of the committee on municipal health department practice. American Journal of Public Health, 14(3):184-187, 1924.

Gregory L Armstrong, Laura A Conn, and Robert W Pinner. Trends in infectious disease mortality in the united states during the 20th century. Jama, 281(1):61-66, 1999.

Martha J Bailey and Andrew Goodman-Bacon. The war on poverty's experiment in public medicine: Community health centers and the mortality of older americans. The American economic review, 105(3):1067-1104, 2015.

Hoyt Bleakley. Disease and development: evidence from hookworm eradication in the american south. The Quarterly Journal of Economics, 122(1):73, 2007.

Hoyt Bleakley. Malaria eradication in the americas: A retrospective analysis of childhood exposure. American economic journal. Applied economics, 2(2), 2010.

Nazmul Chaudhury, Jeffrey Hammer, Michael Kremer, Karthik Muralidharan, and F Halsey Rogers. Missing in action: teacher and health worker absence in developing countries. The Journal of Economic Perspectives, 20(1):91-116, 2006.

Thomas Clasen, Wolf-Peter Schmidt, Tamer Rabie, Ian Roberts, and Sandy Cairncross. Interventions to improve water quality for preventing diarrhoea: systematic review and metaanalysis. $B m j, 334(7597): 782,2007$.

Karen Clay, Werner Troesken, and Michael Haines. Lead and mortality. Review of Economics and Statistics, 96(3):458-470, 2014. 
William J Collins and Melissa A Thomasson. The declining contribution of socioeconomic disparities to the racial gap in infant mortality rates, 1920-1970. Southern Economic Journal, pages 746-776, 2004.

Gretchen A Condran and Eileen Crimmins-Gardner. Public health measures and mortality in us cities in the late nineteenth century. Human Ecology, 6(1):27-54, 1978.

Dora L Costa. Health and the economy in the united states from 1750 to the present. Journal of economic literature, 53(3):503-570, 2015.

Dora L Costa and Matthew E Kahn. Public health and mortality: What can we learn from the past? Public policy and the income distribution, page 359e397, 2006.

Dora L Costa, Matthew E Kahn, et al. Declining mortality inequality within cities during the health transition. American Economic Review, 105(5):564-69, 2015.

David Cutler and Grant Miller. The role of public health improvements in health advances: the twentieth-century united states. Demography, 42(1):1-22, 2005.

David Cutler and Grant Miller. Water, water everywhere. municipal finance and water supply in american cities. In Corruption and Reform: Lessons from America's Economic History, pages 153-184. University of Chicago Press, 2006.

David Cutler, Angus Deaton, and Adriana Lleras-Muney. The determinants of mortality. The Journal of Economic Perspectives, 20(3):97-120, 2006.

Klaus Desmet and Jordan Rappaport. The settlement of the united states, 1800 to 2000: The long transition towards gibrat's law. Journal of Urban Economics, 2015.

Harry Filmore Dowling et al. Fighting infection. Conquests of the Twentieth Century. Harvard University Press, 79 Garden Street, Cambridge, Massachusetts 02138, USA, 1977.

John Duffy. The sanitarians: a history of American public health. University of Illinois Press, 1992.

Esther Duflo, Michael Greenstone, Raymond Guiteras, and Thomas Clasen. Toilets can work: Short and medium run health impacts of addressing complementarities and externalities in water and sanitation. Technical report, National Bureau of Economic Research, 2015.

John A Ferrell, Pauline A Mead, et al. History of county health organizations in the united states 1908-33. Public Health Bulletin, (222), 1936.

Joseph P Ferrie and Werner Troesken. Water and chicago's mortality transition, 1850-1925. Explorations in Economic History, 45(1):1-16, 2008.

Robert W Fogel. Economic growth, population theory, and physiology: The bearing of longterm processes on the. American economic review, 84(3):369-395, 1994.

Raymond Blaine Fosdick. The story of the Rockefeller Foundation. Transaction Publishers, 1952.

Jonathan Fox. Origins and effects of the rural public health programs in north carolina. 2015.

Bess Furman. A Profile of the United States Public Health Service 1798-1948. National Institutes of Health, 1973. 
Sebastian Galiani, Paul Gertler, and Ernesto Schargrodsky. Water for life: The impact of the privatization of water services on child mortality. Journal of political economy, 113(1):83-120, 2005.

Shanti Gamper-Rabindran, Shakeeb Khan, and Christopher Timmins. The impact of piped water provision on infant mortality in brazil: A quantile panel data approach. Journal of Development Economics, 92(2):188-200, 2010.

William E Garnett et al. road to health in rural virginia, 1900-1952. 1954.

Michael Geruso and Dean Spears. Neighborhood sanitation and infant mortality. Technical report, National Bureau of Economic Research, 2015.

Michael R Haines. The relationship between infant and child mortality and fertility: Some historical and contemporary evidence for the united states. From Death to Birth: Mortality Decline and Reproductive Change (Washington, DC: National Academy Press, 1998), pages 227-53, 1998.

Michael R Haines. Historical demographic, economic and social data: The united states, 17901970. Department of Economics. Colgate University, Computer File, 2001a.

Michael R Haines. The urban mortality transition in the united states, 1800-1940. In Annales de démographie historique, number 1, pages 33-64. Belin, 2001b.

Michael R Haines. Historical demographic, economic and social data: The united states, 17901970. Interuniversity Consortium for Political and Social Research, 2001c.

Michael R Haines. Interuniversity consortium for political and social research. historical, demographic, economic, and social data: The united states, 1790-2000 [computer file]. icpsr02896v2. hamilton, ny: Colgate university. Ann Arbor: MI: Interuniversity Consortium for Political and Social Research [producers], 2004.

Derek Headey, John Hoddinott, Disha Ali, Roman Tesfaye, and Mekdim Dereje. The other asian enigma: Explaining the rapid reduction of undernutrition in bangladesh. World Development, 66:749-761, 2015.

Robert Higgs. Mortality in rural america, 1870-1920: Estimates and conjectures. Explorations in Economic History, 10(2):177, 1973.

Seema Jayachandran, Adriana Lleras-Muney, and Kimberly V Smith. Modern medicine and the twentieth century decline in mortality: evidence on the impact of sulfa drugs. American Economic Journal: Applied Economics, 2(2):118-146, 2010.

K.Y. Kentucky State Board of Health. Biennial report of the State Board of Health of Kentucky. 1909.

Miriam King, Steven Ruggles, J Trent Alexander, Sarah Flood, Katie Genadek, Matthew B Schroeder, Brandon Trampe, and Rebecca Vick. Integrated public use microdata series, current population survey: Version 3.0.[machine-readable database]. Minneapolis: University of Minnesota, 20, 2010.

Carl Kitchens. A dam problem: Tva's fight against malaria, 1926-1951. The Journal of Economic History, 73(03):694-724, 2013.

United States. Hygiene Laboratory. Hygienic Laboratory Bulletin. Number v. 35-74. 1909-1910. 
Molly Ladd-Taylor. 'grannies' and'spinsters': Midwife education under the sheppard-towner act. Journal of Social History, 22(2):255-275, 1988.

L. Lumsden. The causation and prevention of typhoid fever with special reference to conditions observed in yakima county washington. Public Health Bulletin, (51), 1911.

L. Lumsden. Report on special studies made in 15 counties, 1914-1916. Public Health Bulletin, (94), 1918.

Leslie Leon Lumsden. Cooperative rural health work of the public health service. Public Health Reports (1896-1970), 1920-30.

MDG. Millennium development goals report. United Nations, 2015.

Edward Meeker. The improving health of the united states, 1850-1915. Explorations in Economic History, 9(4):353, 1972.

Michael Meit and Alana Knudson. Why is rural public health important? a look to the future. Journal of Public Health Management and Practice, 15(3):185-190, 2009.

Martin V. Melosi. The Sanitary City: Urban Infrastructure in America from Colonial Times to the Present. Baltimore, MD: The Johns Hopkins University Press, 2000.

Edward Miguel and Michael Kremer. Worms: identifying impacts on education and health in the presence of treatment externalities. Econometrica, pages 159-217, 2004.

Carolyn M Moehling and Melissa A Thomasson. The political economy of saving mothers and babies: The politics of state participation in the sheppard-towner program. Technical Report 01, 2012.

Carolyn M Moehling and Melissa A Thomasson. Saving babies: The impact of public education programs on infant mortality. Demography, 51(2):367-386, 2014.

Alan L Olmstead and Paul W Rhode. An impossible undertaking: the eradication of bovine tuberculosis in the united states. The Journal of Economic History, 64(03):734-772, 2004.

Thomas Pressly and William H Scofield. Farm real estate values in the United States by counties, 1850-1959. University of Washington Press, 1965.

Jordan Rappaport. Moving to nice weather. Regional Science and Urban Economics, 37(3): 375-398, 2007.

Mazyck P Ravenel. The american public health association, past, present, future. American Journal of Public Health, 11(12):1031-1041, 1921a.

Mazÿck Porcher Ravenel. A half century of public health: jubilee historical volume of the American Public Health Association, in commemoration of the fiftieth anniversary celebration of its foundation, New York City, November 14-18, 1921. New York: American Public Health Association, 1921b.

George Rosen. A history of public health. JHU Press, 2015.

Milton Joseph Rosenau, George Chandler Whipple, John William Trask, and Thomas William Salmon. Preventive medicine and hygiene. D. Appleton, 1921.

Franz Schneider Jr. A survey of the activities of municipal health departments in the united states. American Journal of Public Health, 6(1):1-17, 1916. 
Wilson G Smillie. Public health: Its promise for the future: A chronicle of the development of public health in the united states, 1607-1914. In Public health: Its promise for the future: A chronicle of the development of public health in the United States, 1607-1914. Macmillan, 1955 .

Dean Spears and Sneha Lamba. Effects of early-life exposure to rural sanitation on childhood cognitive skills: evidence from indias total sanitation campaign, 2012.

Milton Terris. The epidemiologic revolution, national health insurance and the role of health departments. American Journal of public health, 66(12):1155-1164, 1976.

Werner Troesken. Typhoid rates and the public acquisition of private waterwork, 1880-1920. The Journal of Economic History, 59(04):927-948, 1999.

Werner Troesken. Race, disease, and the provision of water in american cities, 1889-1921. The Journal of Economic History, 61(03):750-776, 2001.

Werner Troesken and Rick Geddes. Municipalizing american waterworks, 1897-1915. Journal of Law, Economics, and Organization, 19(2):373-400, 2003.

UNICEF. Levels and trends in child mortality report. 2015.

Bureau of the Census United States Vital Statistics. Mortality Statistics: Vital Statistics of the United States: 1890-1938. United States Bureau of the Census, 1890-1938.

USPHS. Public health bulletin. Number varied. in Public health bulletin. U.S. Government Printing Office, varied.

John W Ward, Christian Warren, et al. Silent victories: the history and practice of public health in twentieth-century America. Oxford University Press, Inc, 2007.

WHO. Department of Maternal, Newborn, Child and Adolescent Health (MCA) Progress report. World Health Organization, 2016.

Jennyfer Wolf, Annette Prüss-Ustün, Oliver Cumming, Jamie Bartram, Sophie Bonjour, Sandy Cairncross, Thomas Clasen, John M Colford, Valerie Curtis, Jennifer France, et al. Systematic review: assessing the impact of drinking water and sanitation on diarrhoeal disease in lowand middle-income settings: systematic review and meta-regression. Tropical Medicine 8 International Health, 19(8):928-942, 2014. 


\section{A Appendix}

\section{A.1 Original Tables}

Figure A.1: Detail of Health Department Activities (Lumsden [1920-30])

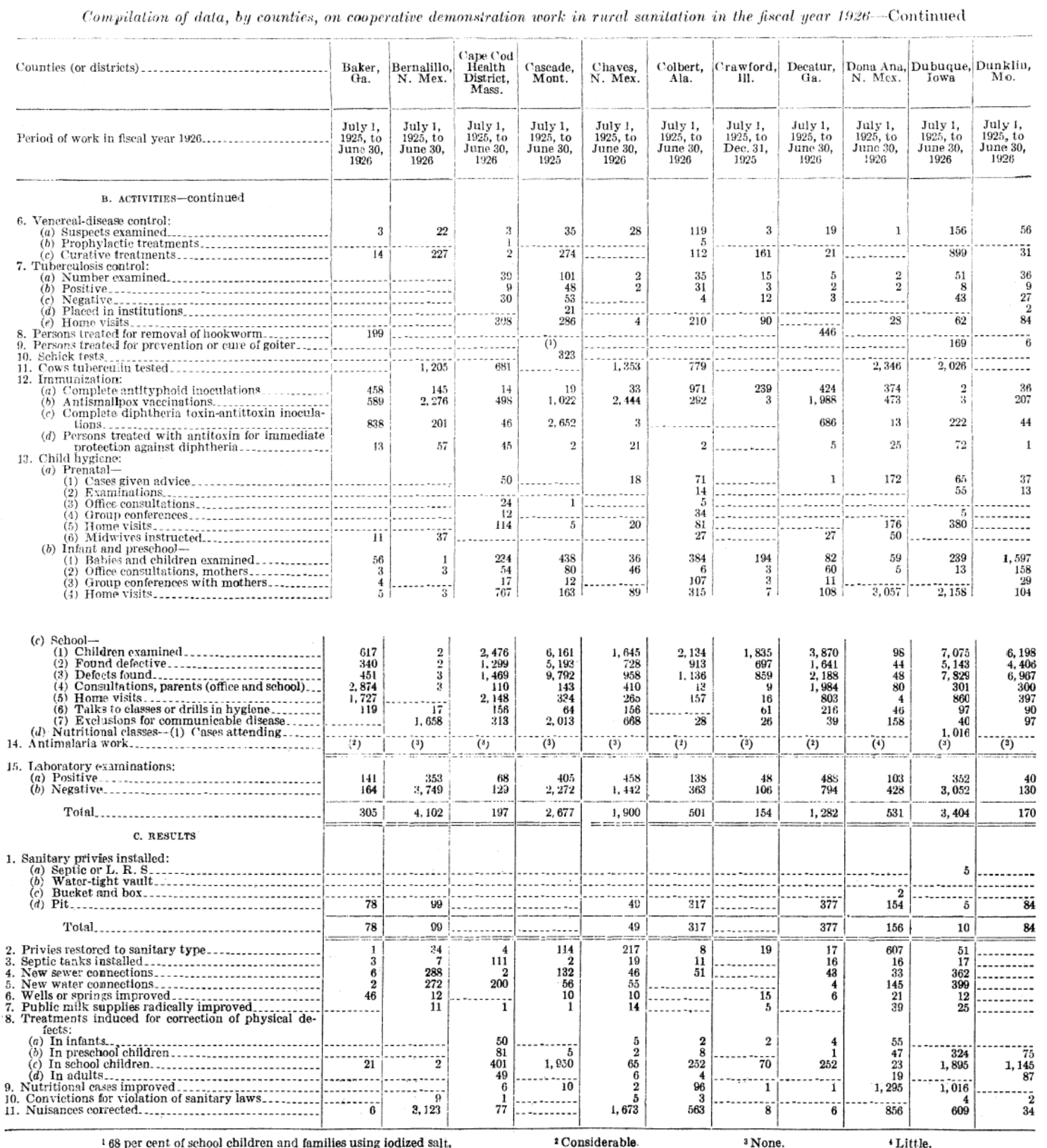


Figure A.2: Original Health Department Record for Alabama and Louisiana (Public Health Bulletin 222)

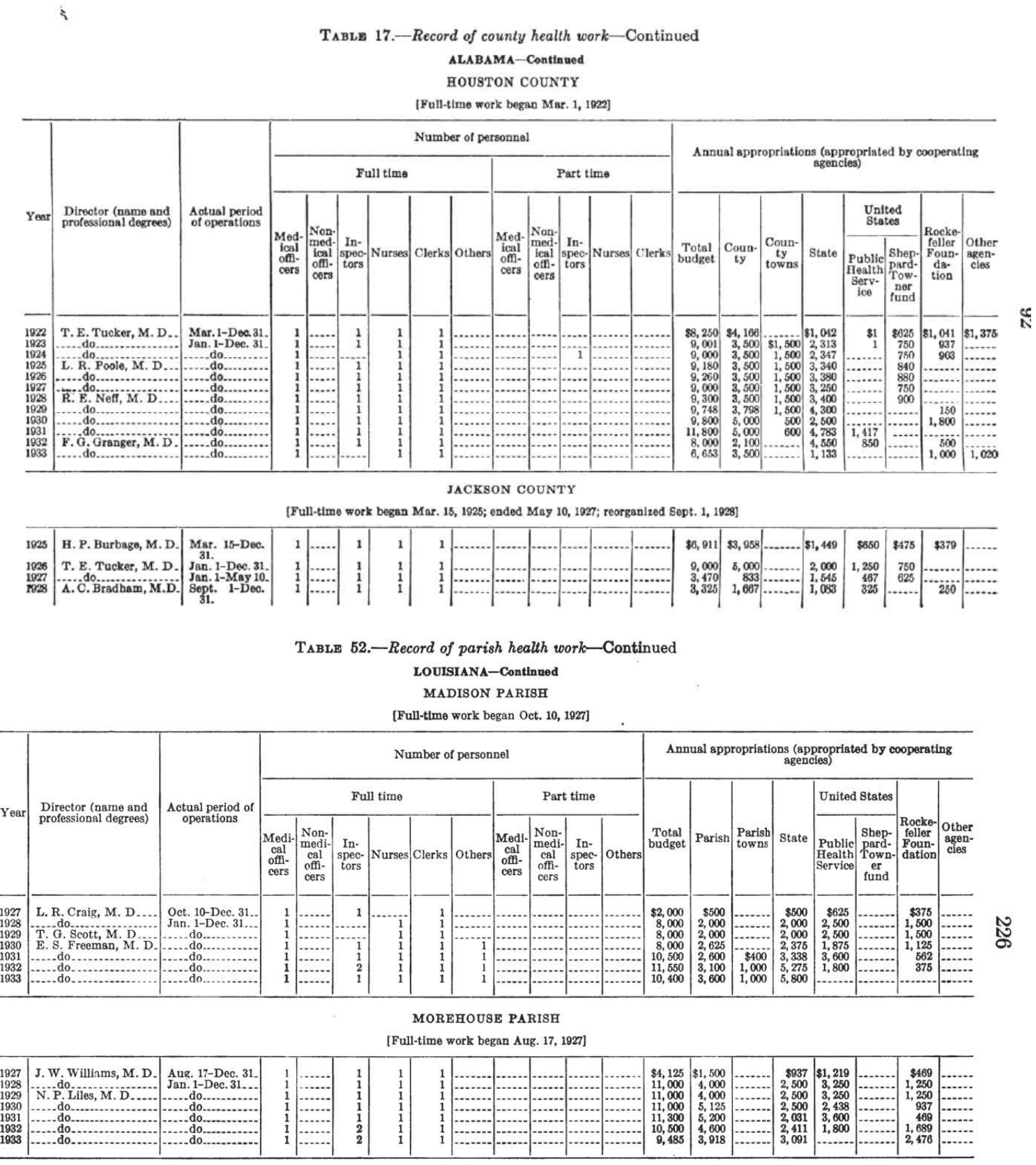


Figure A.3: Example of Overall Mortality (U.S. Vital Statistics)

TABLE I B.-POPULATION, TOTAL DEATHS, DEATHS OF RESIDENTS, AND DEATH RATES PER 1,000 POPULATION, IN EACH CITY AND THE RURAL PART OF EACH COUNTY: 1926-Continued

[See note at head of this table, p. 4]

\begin{tabular}{|c|c|c|c|c|c|c|c|c|c|c|c|c|c|c|c|c|c|}
\hline \multirow{3}{*}{ AREA AND COLOR } & \multirow{3}{*}{$\begin{array}{c}\text { Kstl- } \\
\text { mpated } \\
\text { popula- } \\
\text { toon. } \\
\text { July i. } \\
\text { 1926 }\end{array}$} & \multicolumn{4}{|c|}{1926} & \multirow{3}{*}{ AREA AND COLOR } & \multirow{3}{*}{$\begin{array}{c}\text { Esti- } \\
\text { matied } \\
\text { popula- } \\
\text { tion, } \\
\text { July } 1 . \\
1926\end{array}$} & \multicolumn{4}{|c|}{1926} & \multirow{3}{*}{ AREA AND COLOR } & \multirow{3}{*}{$\begin{array}{c}\text { Esti- } \\
\text { mated } \\
\text { Dopula- } \\
\text { toon, } \\
\text { July } 1 \text {, } \\
1926\end{array}$} & \multicolumn{4}{|c|}{1926} \\
\hline & & \multicolumn{2}{|c|}{$\begin{array}{l}\text { Total } \\
\text { deaths }\end{array}$} & \multicolumn{2}{|c|}{$\begin{array}{l}\text { Deaths of } \\
\text { residents : }\end{array}$} & & & \multicolumn{2}{|c|}{$\begin{array}{l}\text { Total } \\
\text { deaths }\end{array}$} & \multicolumn{2}{|c|}{$\begin{array}{l}\text { Deaths of } \\
\text { residents : }\end{array}$} & & & \multicolumn{2}{|c|}{$\begin{array}{l}\text { Total } \\
\text { deaths }\end{array}$} & \multicolumn{2}{|c|}{$\begin{array}{l}\text { Deaths of } \\
\text { residents } 1\end{array}$} \\
\hline & & $\underset{\text { ber }}{\text { Num. }}$ & $\begin{array}{c}\text { Rate } \\
\text { per } \\
1,000 \\
\text { pop- } \\
\text { ulp. } \\
\text { tion }\end{array}$ & $\underset{\substack{\text { Num- } \\
\text { ber }}}{ }$ & $\begin{array}{l}\text { Rate } \\
\text { per } \\
1,000 \\
\text { pop- } \\
\text { ula- } \\
\text { tion }\end{array}$ & & & $\underset{\text { bet }}{\text { Num- }}$ & $\begin{array}{l}\text { Rate } \\
\text { per } \\
\text { l. woo s } \\
\text { pop- } \\
\text { ula- } \\
\text { tion }\end{array}$ & $\underset{\text { Ner }}{\text { Num. }}$ & $\begin{array}{l}\text { Rate } \\
\text { per } \\
\text { 1,000 } \\
\text { pop. } \\
\text { ula. } \\
\text { tion }\end{array}$ & & & $\underset{\text { ber }}{\text { Num. }}$ & $\begin{array}{l}\text { Rate } \\
\text { per } \\
\text { p., } 000 \text { : } \\
\text { pop. } \\
\text { ula. } \\
\text { tion }\end{array}$ & Wer- & $\begin{array}{l}\text { Rate } \\
\text { per } \\
\text { pero } \\
\text { pop- } \\
\text { ula- } \\
\text { tion }\end{array}$ \\
\hline $\begin{array}{l}\text { Culpors } \\
\text { TIKS (RUH }\end{array}$ & & & & & & $(\boldsymbol{R} \cup \mathrm{RA}$ & & & & & & (BUH & & & & & \\
\hline $\begin{array}{l}\text { Terced } \\
\text { Modoc. } \\
\text { Mono } \\
\text { White } \\
\text { Colored.............. } \\
\text { Monterey }\end{array}$ & $\begin{array}{r}30,900 \\
13,425 \\
3900 \\
690 \\
250 \\
30,200\end{array}$ & $\begin{array}{r}285 \\
50 \\
3 \\
\vdots \\
406\end{array}$ & $\begin{array}{r}9.2 \\
9.2 \\
3.1 \\
2.9 \\
3.8 \\
13.3\end{array}$ & $\begin{array}{r}294 \\
53 \\
4 \\
3 \\
1 \\
407\end{array}$ & $\begin{array}{l}9.5 \\
9.8 \\
4.2 \\
4.3 \\
3.8 \\
13.3\end{array}$ & $\begin{array}{l}\text { Kit Carson... } \\
\text { Lake ......... } \\
\text { Las Plata..... } \\
\text { Larimer..... } \\
\text { Las Animas. } \\
\text { Lineoln ....... }\end{array}$ & $\begin{array}{r}2,900 \\
8,6,600 \\
11,3000 \\
20,000 \\
31,500 \\
2,800\end{array}$ & $\begin{array}{r}54 \\
171 \\
182 \\
316 \\
312 \\
48\end{array}$ & $\begin{array}{r}5,5 \\
25,8 \\
15.8 \\
10,7 \\
0.9 \\
4.9\end{array}$ & $\begin{array}{r}67 \\
169 \\
183 \\
329 \\
328 \\
59\end{array}$ & $\begin{array}{r}6.8 \\
25.5 \\
15.9 \\
11.1 \\
10.4 \\
6.0\end{array}$ & $\begin{array}{l}\text { Calkoun.... } \\
\text { White... } \\
\text { Colored... } \\
\text { Charlotte ... } \\
\text { White... } \\
\text { Colored. }\end{array}$ & $\begin{array}{l}\text { (in) } \\
\text { (II) } \\
\text { (ig) } \\
\text { (II) } \\
\text { (II) } \\
\text { (ii) }\end{array}$ & $\begin{array}{l}38 \\
77 \\
11 \\
51 \\
34 \\
17\end{array}$ & 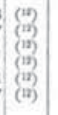 & $\begin{array}{l}66 \\
54 \\
12 \\
86 \\
40 \\
16\end{array}$ & $\begin{array}{l}\text { (19) } \\
\text { III) } \\
\text { III) } \\
\text { (11) } \\
\text { (19) } \\
\text { (19) }\end{array}$ \\
\hline $\begin{array}{l}\text { ape } \\
\text { evad } \\
\text { runge }\end{array}$ & $\begin{array}{r}21,300 \\
-10.850 \\
58,800 \\
18,800\end{array}$ & $\begin{array}{l}501 \\
176 \\
74 \\
399\end{array}$ & $\begin{array}{l}27.7 \\
15.7 \\
12.7 \\
21.7\end{array}$ & $\begin{array}{l}589 \\
184 \\
747 \\
296\end{array}$ & $\begin{array}{l}27.7 \\
17.0 \\
12.7 \\
15.7\end{array}$ & $\begin{array}{l}\text { Logan... } \\
\text { Mess... } \\
\text { Mineril } \\
\text { Moffat. }\end{array}$ & $\begin{array}{l}24,400 \\
22,3700 \\
779\end{array}$ & $\begin{array}{r}148 \\
294 \\
99\end{array}$ & $\begin{array}{r}6.1 \\
13.2 \\
11.6 \\
(4)\end{array}$ & $\begin{array}{r}157 \\
300 \\
10 \\
31\end{array}$ & $\left\{\begin{array}{l}6.4 \\
13.5 \\
12.8 \\
(11.8\end{array}\right.$ & $\begin{array}{l}\text { Citrus } \\
\text { White } \\
\text { Colored }\end{array}$ & $\begin{array}{r}5,400 \\
3,300 \\
1,900 \\
\end{array}$ & $\begin{array}{l}67 \\
33 \\
24 \\
80\end{array}$ & $\begin{array}{l}10.6 \\
2.4 \\
12.6 \\
16.9\end{array}$ & & $\begin{array}{l}11.1 \\
9.1 \\
14.7 \\
170\end{array}$ \\
\hline $\begin{array}{l}\text { White.......... } \\
\text { Colored........... }\end{array}$ & $\begin{array}{r}16,300 \\
2,500\end{array}$ & 5 & $\begin{array}{l}21.3 \\
22.3 \\
13.2\end{array}$ & $\begin{array}{r}271 \\
25\end{array}$ & 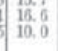 & $\begin{array}{l}\text { Montexima... } \\
\text { Montrose.... }\end{array}$ & $\begin{array}{r}7,100 \\
12,900\end{array}$ & 99 & $\begin{array}{r}13.9 \\
8.6\end{array}$ & $\begin{array}{l}31 \\
100 \\
116\end{array}$ & $\begin{array}{r}14.1 \\
9.0\end{array}$ & $\begin{array}{l}\text { White. } \\
\text { Colored. }\end{array}$ & 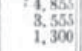 & $\begin{array}{l}8.2 \\
\frac{8}{26} \\
26\end{array}$ & $\begin{array}{l}16.9 \\
15.8 \\
20.0\end{array}$ & $\begin{array}{l}6: \\
26:\end{array}$ & $\begin{array}{l}17.9 \\
17.2 \\
20.0\end{array}$ \\
\hline $\begin{array}{l}\text { Plumns } \\
\text { Riverside.......................... }\end{array}$ & $\begin{aligned} 6,000 \\
35,000 \\
33,200\end{aligned}$ & $\begin{array}{l}83 \\
458 \\
249\end{array}$ & $\begin{array}{l}13.8 \\
11.8 \\
7.5\end{array}$ & $\begin{array}{r}90 \\
503 \\
297\end{array}$ & $\begin{array}{l}15.0 \\
13.0 \\
8.9\end{array}$ & & $\begin{array}{l}20,300 \\
\text { (ii) } \\
\text { (i) }\end{array}$ & $\begin{array}{r}164 \\
280 \\
25\end{array}$ & $\mid \begin{array}{c}8.0 \\
\text { (ii) } \\
2.5\end{array}$ & $\begin{array}{r}107 \\
294 \\
25\end{array}$ & $\begin{array}{l}8.1 \\
(1 i j) \\
2.5\end{array}$ & $\begin{array}{l}\text { Colliet - } \\
\text { White. } \\
\text { Colored }\end{array}$ & (1) & & (18) & & (19) \\
\hline $\begin{array}{l}\text { Whito } \\
\text { Colored .......... } \\
\text { San Benito........... }\end{array}$ & $\begin{array}{r}25,800 \\
7,400 \\
8,600\end{array}$ & $\begin{array}{l}196 \\
51 \\
13:\end{array}$ & $\begin{array}{r}7.7 \\
6.9 \\
14.3\end{array}$ & $\begin{array}{r}229 \\
68 \\
137\end{array}$ & $\begin{array}{r}8.9 \\
0.2 \\
14.3\end{array}$ & $\begin{array}{l}\text { Park } \\
\text { Phili........... } \\
\text { Pitkins...... }\end{array}$ & 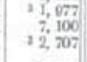 & $\begin{array}{l}12 \\
56 \\
27\end{array}$ & $\begin{array}{r}6.1 \\
7.9 \\
10.0\end{array}$ & $\begin{array}{l}13 \\
59 \\
28\end{array}$ & $\begin{array}{r}6.6 \\
8.3 \\
10.3\end{array}$ & $\begin{array}{l}\text { Columbia....... } \\
\text { White. } \\
\text { Colored....... }\end{array}$ & $\begin{array}{l}15,900 \\
8,000 \\
7,100\end{array}$ & $\begin{array}{l}2 i 23 \\
122 \\
103\end{array}$ & $\begin{array}{l}14.2 \\
13.9 \\
14.5\end{array}$ & $\begin{array}{c}230 \\
121 \\
109\end{array}$ & $\begin{array}{l}74.5 \\
13.8 \\
15.4\end{array}$ \\
\hline $\begin{array}{l}\text { San Bernardino } \\
\text { San Diego } \\
\text { San Josquin........ } \\
\text { White. } \\
\text { Colored........ } \\
\text { San Luis Obispo.. }\end{array}$ & 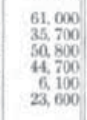 & $\mid \begin{array}{r}1,043 \\
504 \\
1.010 \\
896 \\
111 \\
336\end{array}$ & $\begin{array}{l}17.1 \\
14.1 \\
19.9 \\
30.1 \\
18.2 \\
14.2\end{array}$ & $\begin{array}{r}1.055 \\
515 \\
1.014 \\
902 \\
112 \\
338\end{array}$ & $\begin{array}{l}17.5 \\
14.4 \\
20.0 \\
20.2 \\
18.4 \\
14.3\end{array}$ & $\begin{array}{l}\text { Prowers... } \\
\text { Pueblo } \\
\text { Rio Blinco } \\
\text { Rio Grande } \\
\text { Rout }\end{array}$ & $\begin{array}{r}16,707 \\
17,700 \\
3,700 \\
8,700 \\
\text { (u) } \\
5,000 \\
+1,700\end{array}$ & $\begin{array}{r}128 \\
425 \\
10 \\
123 \\
99 \\
28 \\
19\end{array}$ & $\begin{array}{l}7.7 \\
24.4 \\
2.7 \\
14.7 \\
(12) \\
5.6 \\
11.2\end{array}$ & $\begin{array}{r}129 \\
47 \\
10 \\
133 \\
102 \\
28 \\
19\end{array}$ & $\begin{array}{l}7.7 \\
25.7 \\
2.7 \\
15.3 \\
(12.3 \\
5.6 \\
11.2\end{array}$ & $\begin{array}{l}\text { Dade } \\
\text { Whitie. } \\
\text { Colored. } \\
\text { De Soto.... } \\
\text { White. } \\
\text { Colored }\end{array}$ & $\begin{array}{l}\text { (8) } \\
\text { (3) } \\
\text { (5) } \\
\text { (9in) } \\
\text { (ii) }\end{array}$ & $\begin{array}{r}336 \\
204 \\
72 \\
145 \\
103 \\
42\end{array}$ & 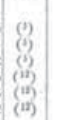 & $\begin{array}{r}434 \\
321 \\
103 \\
118 \\
82 \\
36\end{array}$ & $\begin{array}{l}\text { (5) } \\
\text { (1) } \\
\text { (1) } \\
\text { (1) } \\
\text { (1) }\end{array}$ \\
\hline $\begin{array}{l}\text { San Mate } \\
\text { Sants Bar } \\
\text { Santa Clu } \\
\text { Santa Cru } \\
\text { shasto... } \\
\text { Sierra... }\end{array}$ & $\begin{array}{r}43,600 \\
25,200 \\
67,900 \\
15,500 \\
+13,361 \\
1,783\end{array}$ & $\mid \begin{array}{r}383 \\
285 \\
1,253 \\
221 \\
174 \\
28\end{array}$ & $\begin{array}{l}13.4 \\
10.1 \\
19.0 \\
14.3 \\
13.0 \\
15.7\end{array}$ & $\begin{array}{r}520 \\
251 \\
1.264 \\
232 \\
150 \\
200\end{array}$ & $\mid \begin{array}{l}13.7 \\
10.7 \\
18.6 \\
15.0 \\
13.5 \\
16.3\end{array}$ & $\begin{array}{l}\text { San Migu } \\
\text { gedgwick } \\
\text { summinit. } \\
\text { Teller } \\
\text { Wushingt } \\
\text { Weld }\end{array}$ & $\begin{array}{l}5,700 \\
5,000 \\
1,724 \\
16,60 \\
14,700 \\
51,200\end{array}$ & $\begin{array}{r}55 \\
30 \\
27 \\
65 \\
51 \\
339\end{array}$ & $\begin{array}{r}2.6 \\
7.8 \\
15.7 \\
9.7 \\
2.7 \\
6.6\end{array}$ & $\begin{array}{r}56 \\
43 \\
31 \\
69 \\
55 \\
417\end{array}$ & $\begin{array}{r}9.8 \\
8.6 \\
18.0 \\
10.3 \\
3.7 \\
8.1\end{array}$ & $\begin{array}{l}\text { Dixie } \\
\text { Whitie } \\
\text { Colced: } \\
\text { Dusal } \\
\text { White } \\
\text { Colored. }\end{array}$ & 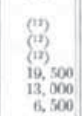 & $\begin{array}{r}22 \\
14 \\
8 \\
317 \\
104 \\
123\end{array}$ & $\begin{array}{l}\text { (19) } \\
\text { (in) } \\
\text { ia) } \\
16.3 \\
14.9 \\
18.9\end{array}$ & $\begin{array}{r}23 \\
15 \\
8 \\
350 \\
238 \\
142\end{array}$ & $\begin{array}{l}19 \\
119 \\
119 \\
10.5 \\
18.3 \\
21.8\end{array}$ \\
\hline $\begin{array}{l}\text { Siskiyou. } \\
\text { solano } \\
\text { sonoma. }\end{array}$ & $\begin{array}{r}18,545 \\
21,700 \\
54,600\end{array}$ & $\mid \begin{array}{l}258 \\
150 \\
811\end{array}$ & $\begin{array}{r}13.6 \\
6.9 \\
14.9\end{array}$ & $\begin{array}{l}206 \\
153 \\
816\end{array}$ & 14.3 & CONKECTICUT COUN- & 17,300 & n & 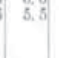 & & 5 & Fsombia & $\begin{array}{l}: 18,152 \\
11,027\end{array}$ & 1if & 9.0 & $\begin{array}{l}167 \\
114\end{array}$ & $\begin{array}{l}9.2 \\
8.1\end{array}$ \\
\hline
\end{tabular}


Figure A.4: Example of Infant Mortality (U.S. Vital Statistics)

SUMMARY AND RATE TABLES

TABLE I.-POPULATION, BIRTHS AND DEATHS WITH RATES PER 1,000 POPULATION, INFANT MORTALITY, AND STILLBIRTHS, IN THE BIRTH REGISTRATION AREA IN CONTINENTAL UNITED STATES AND ITS [See note at head of this table, p. 2 ]

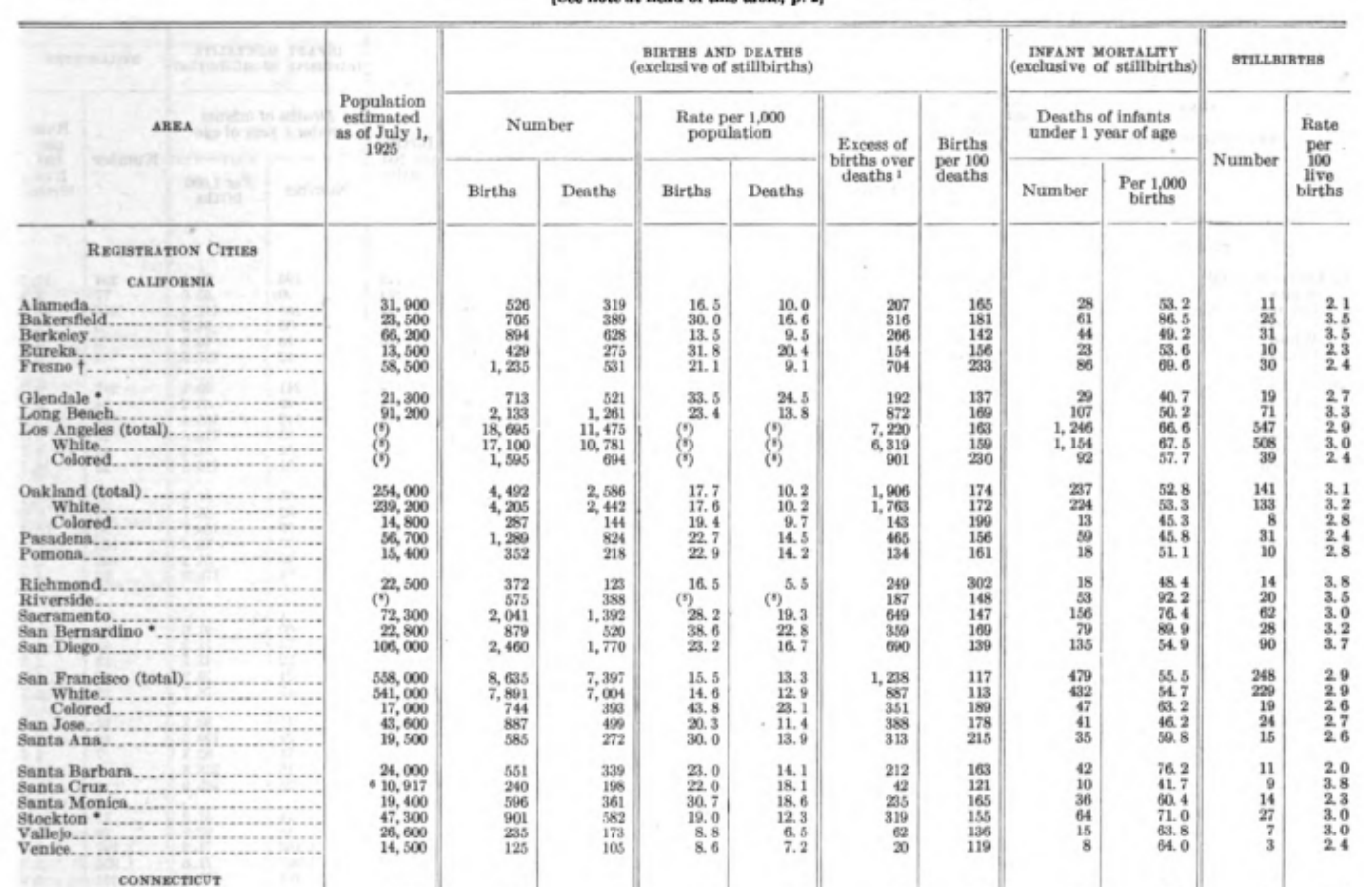




\section{A.2 Additional Tables}

Figure A.5: Main Mortality Measures
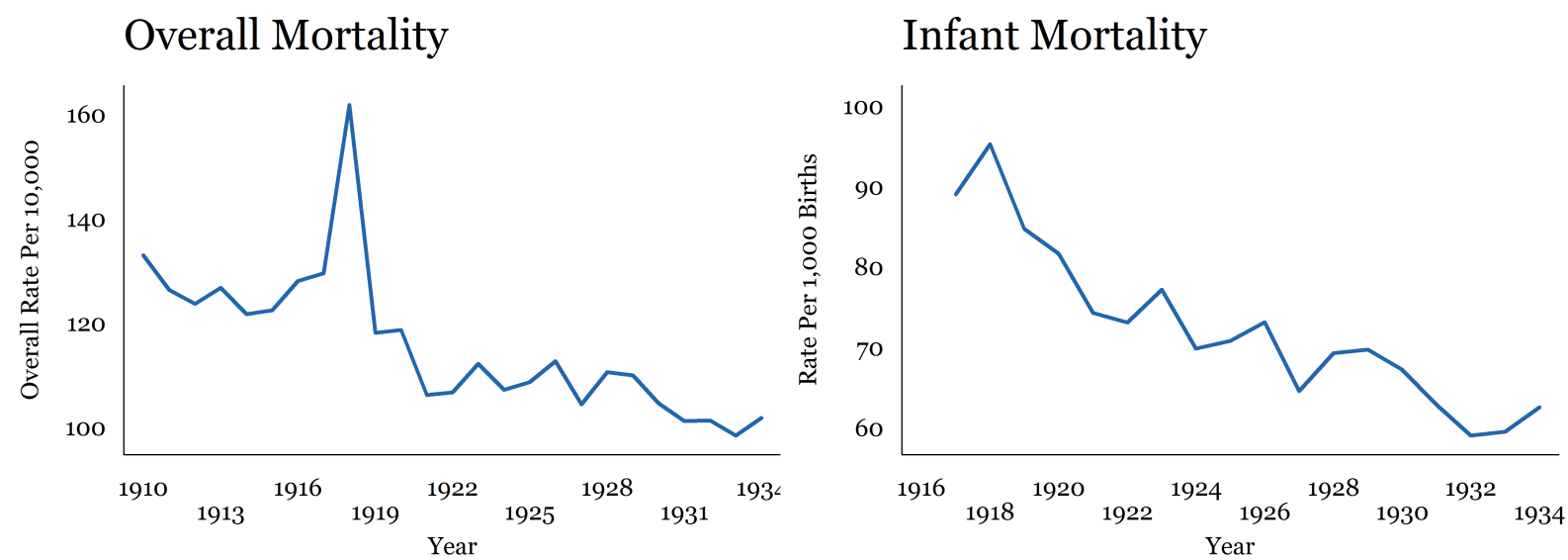

Stillbirth Rate

Child Mortality
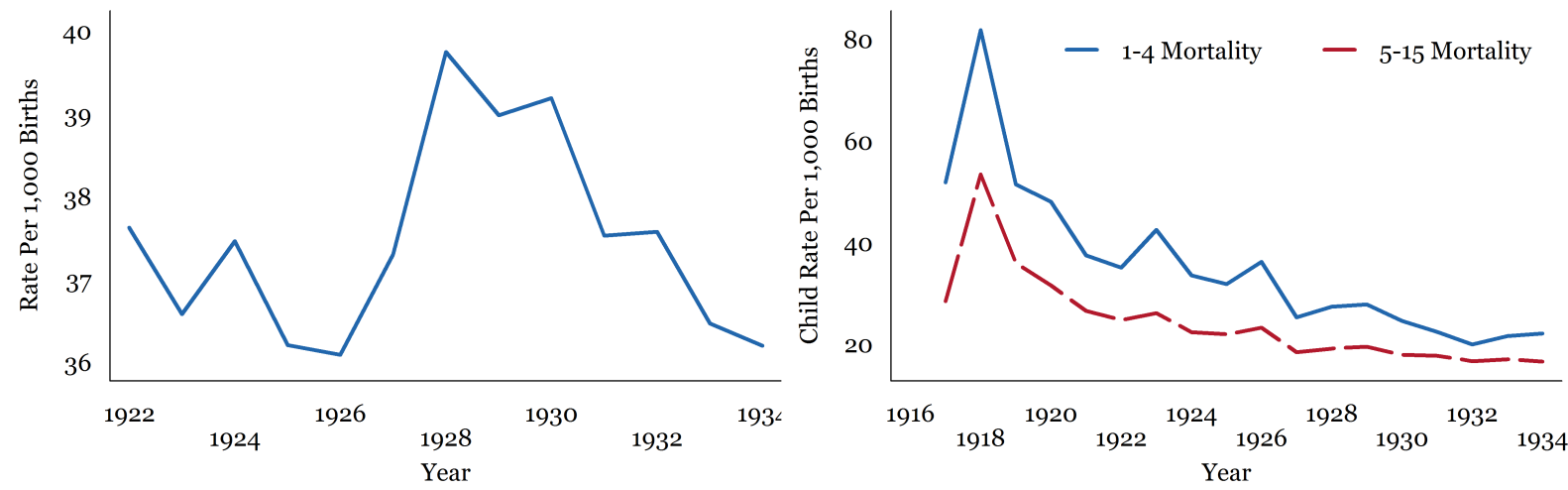

Notes: Data source from US Vital Statistics. Crude mortality is defined per 10,000. Infant mortality, stillbirths, and child mortality are defined per 1,000 births. 1918 is included. 
Table 14: State Year of Initiation: Overall Mortality and Infant Mortality All 38 States

\begin{tabular}{|c|c|c|c|c|c|c|c|}
\hline & \multirow[b]{2}{*}{ \# Counties } & \multicolumn{3}{|c|}{ Overall Mortality } & \multicolumn{3}{|c|}{ Infant Mortality } \\
\hline & & Initial Year & Initial Rate & 1934 Rate & Initial Year & Initial Rate & 1934 Rate \\
\hline $\mathrm{AL}$ & 67 & 1925 & 103.8 & 96.6 & 1927 & 61.7 & 63.9 \\
\hline $\mathrm{AR}$ & 75 & 1927 & 89.9 & 76.9 & 1927 & 59.0 & 52.0 \\
\hline $\mathrm{AZ}$ & 13 & 1926 & 98.9 & 95.2 & 1926 & 124.8 & 108.0 \\
\hline $\mathrm{CA}$ & 57 & 1910 & 123.0 & 115.6 & 1919 & 78.8 & 63.3 \\
\hline $\mathrm{CO}$ & 58 & 1910 & 125.6 & 105.4 & 1928 & 91.2 & 77.9 \\
\hline $\mathrm{DE}$ & 3 & 1919 & 165.6 & 128.9 & 1921 & 102.8 & 68.7 \\
\hline FL & 41 & 1919 & 116.7 & 115.1 & 1924 & 79.5 & 68.8 \\
\hline GA & 129 & 1922 & 87.1 & 101.8 & 1928 & 76.6 & 76.1 \\
\hline IA & 99 & 1923 & 93.1 & 95.1 & 1924 & 50.4 & 46.8 \\
\hline ID & 17 & 1922 & 74.3 & 90.6 & 1926 & 62.8 & 51.4 \\
\hline IL & 102 & 1918 & 140.5 & 115.1 & 1922 & 68.3 & 58.4 \\
\hline IN & 92 & 1910 & 127.3 & 123.1 & 1917 & 77.6 & 52.6 \\
\hline KS & 105 & 1914 & 92.4 & 93.9 & 1917 & 73.0 & 44.1 \\
\hline KY & 117 & 1911 & 123.6 & 100.5 & 1917 & 84.5 & 62.5 \\
\hline LA & 59 & 1918 & 153.6 & 80.5 & 1927 & 72.6 & 62.5 \\
\hline MA & 13 & 1910 & 161.5 & 120.8 & 1917 & 91.3 & 48.8 \\
\hline MD & 21 & 1910 & 132.2 & 110.7 & 1917 & 123.3 & 74.2 \\
\hline MI & 83 & 1910 & 132.9 & 114.5 & 1917 & 80.5 & 51.3 \\
\hline MN & 85 & 1910 & 101.5 & 91.8 & 1917 & 63.8 & 47.5 \\
\hline MO & 114 & 1911 & 119.7 & 114.2 & 1927 & 57.2 & 63.9 \\
\hline MS & 72 & 1919 & 118.7 & 96.1 & 1921 & 66.2 & 62.8 \\
\hline $\mathrm{MT}$ & 17 & 1910 & 88.1 & 95.7 & 1922 & 67.4 & 54.9 \\
\hline $\mathrm{NC}$ & 95 & 1916 & 124.3 & 95.7 & 1917 & 95.8 & 73.8 \\
\hline NM & 21 & 1929 & 143.7 & 128.2 & 1929 & 144.1 & 129.3 \\
\hline NY & 57 & 1910 & 159.6 & 129.8 & 1917 & 85.4 & 52.2 \\
\hline $\mathrm{OH}$ & 88 & 1910 & 127.7 & 107.9 & 1917 & 79.2 & 53.9 \\
\hline OK & 76 & 1928 & 81.0 & 75.0 & 1928 & 66.8 & 56.2 \\
\hline OR & 34 & 1918 & 116.7 & 93.2 & 1919 & 57.5 & 42.8 \\
\hline PA & 66 & 1910 & 143.9 & 103.3 & 1917 & 109.5 & 55.6 \\
\hline $\mathrm{SC}$ & 38 & 1916 & 129.4 & 107.4 & 1919 & 111.1 & 80.8 \\
\hline SD & 62 & 1930 & 76.0 & 83.1 & 1932 & 49.8 & 57.8 \\
\hline $\mathrm{TN}$ & 95 & 1917 & 124.1 & 96.1 & 1927 & 66.6 & 65.8 \\
\hline $\mathrm{TX}$ & 239 & 1933 & 84.7 & 85.5 & 1933 & 68.4 & 65.5 \\
\hline UT & 27 & 1910 & 98.4 & 77.2 & 1917 & 70.5 & 51.6 \\
\hline VA & 96 & 1913 & 126.7 & 111.0 & 1917 & 90.2 & 69.7 \\
\hline WA & 38 & 1910 & 91.5 & 93.1 & 1917 & 74.5 & 46.3 \\
\hline WV & 55 & 1925 & 95.1 & 88.8 & 1925 & 76.8 & 63.3 \\
\hline WY & 11 & 1922 & 82.0 & 86.3 & 1922 & 75.8 & 54.5 \\
\hline
\end{tabular}

Observations $\quad 38$

Notes: Data for 38 available states, sourced from U.S. Mortality Records. Column (2) reports the average number of counties in the state. Columns (3) and (6) report the first year states provided mortality statistics. Columns (4) and (7) report the initial mortality rate. Columns (5) and (8) report the mortality rate at the end of the period considered, 1934. Infant mortality is the rate is per 1,000 births. Overall mortality is the rate per 10,000 individuals. 


\section{A.3 Data Sources}

Data utilized is described in this section. Key definitions, dates, and external information are also listed and explained.

\section{Mortality Rates}

Overall mortality and by cause mortality come from the Vital Statistics of the United States. Available from the Centers for Disease Control at this address http://www.cdc.gov/nchs/products/vsus/vsus_ 1890_1938.htm

- Overall Mortality Rate by City and County:

1. Mortality Rates 1910-1920. With Population of the Federal Censuses of 1910 and 1920 and Intercensal Estimates of Population. Table 1.

2. Mortality Statistics, 1921-1933. Table 1B, years 1922-1926, 1933. Table 1C 1927. Table 2 1931-1932.

3. Birth, Stillbirth, and Infant Mortality Statistics 1918-1934. Table 1.

- Mortality Rate by Cause

1. Mortality Statistics 1900-1909. Table 4, 1900-1909.

2. Mortality Statistics 1910-1915. Table 5, 1914-1915. Table 2, 1910-1913.

3. State level by-cause data is from the NBER at

http://www.nber.org/data/vital-statistics-deaths-historical/.

\section{Population Data}

Decennial County Population Data is from the NBER at http://www.nber.org/data/census_pop. html. This data is used for counties where population is missing from the Death statistics. This data is averaged over the 10 years between censuses.

\section{County Level Health Department Data}

All information regarding the county level health department initiatives, including the estimates for the budget and the number of staff employed, is available from the NIH at http://www.ncbi.nlm.nih.gov/ pmc/journals/427/

\section{County-Level Characteristics}

IPUMS 1\% from King et al. [2010] available at https://usa.ipums.org/usa/ and ICPSR \#2896 from Haines [2001c] available at https://www.icpsr.umich.edu/icpsrweb/ICPSR/studies/2896. 